\title{
PRIMO LEVI Y EL ESTADO DE ISRAEL Análisis de una relación compleja a través de sus documentos.
}

\author{
Angelo Valastro Canale ${ }^{1}$ \\ Universidad Pontificia de Comillas
}

\section{Resumen:}

En 2019 se celebra el primer centenario del nacimiento de Primo Levi (1919-1987), testigo imprescindible de la tragedia de Auschwitz y uno de los intérpretes más lúcidos de todo el siglo XX. El artículo se propone ofrecer al lector español un breve análisis de la evolución de la visión que el autor de "Si esto es un hombre" tuvo de la realidad política del Estado de Israel a lo largo de su vida, desde la idealización juvenil hasta la identificación madura del "baricentro del judaísmo" en el territorio inmaterial de la Diáspora. Dicho análisis se llevará a cabo a través de la lectura de algunos de los numerosos textos dedicados por Levi a la cuestión, textos en su mayoría de difícil acceso y, salvo prueba contraria, inéditos en lengua española.

Palabras Clave: Primo Levi, Israel, Judaísmo, diáspora, siglo XX

Title in English: Primo Levi and the State of Israel. Analysis of a complex relationship through his documents.

\section{Abstract:}

In 2019, we remember the first centenary of Primo Levi (1919-1987), an essential witness of the Auschwitz tragedy and one of the most lucid interpreters of the entire 20th century. This paper aims to offer the Spanish reader a brief analysis of the vision the author of "If this is a man" had of the political reality of the State of Israel during his lifetime, from the youthful idealization to the mature identification of the centre of gravity of Judaism in the immaterial territory of the Diaspora. This analysis will be carried out through the reading of some of the numerous texts dedicated by Levi to this topic. These texts are mostly difficult to access and, unless proven otherwise, unpublished in Spanish.

Key Words: Primo Levi, Israel, Judaism, diaspora, Palestine, 20th century

Copyright (C) UNISCI, 2019.

Las opiniones expresadas en estos artículos son propias de sus autores, y no reflejan necesariamente la opinión de UNISCI. The views expressed in these articles are those of the authors, and do not necessarily reflect the views of UNISCI.

\footnotetext{
${ }^{1}$ Angelo Valastro Canale es profesor de Lenguas clásicas y Filosofía en la Facultad de Ciencias humanas y sociales de la Universidad Pontificia Comillas.

E-mail: <avalastro@comillas.edu>

DOI: http://dx.doi.org/10.31439/UNISCI-66
} 


\section{Introducción ${ }^{2}$}

La bibliografía relativa a la vida y a la obra de Primo Levi (1919-1987), uno de los testigos más lúcidos y refinados de todo el siglo XX, crece año tras año de manera exponencial ${ }^{3}$. Con ocasión del primer centenario de su nacimiento, se ha considerado interesante ofrecer al lector español un breve análisis de la evolución de la visión que el autor de Si esto es un hombre tuvo de la realidad política del Estado de Israel a lo largo de su vida. Dicho análisis se llevará a cabo a través de la lectura de algunos de los numerosos textos dedicados por Levi a la cuestión, textos en su mayoría de difícil acceso y, salvo prueba contraria, inéditos en lengua española.

Después de examinar sintéticamente el problema de la formación de la conciencia cultural del autor (cap. 1), se presentarán cronológicamente las etapas fundamentales de la mencionada evolución: la fase de idealización de Israel, desde los años treinta hasta la llamada "Guerra de los Seis Días" (cap. 2); la pausa de reflexión de los años setenta, contemporánea a la crisis de la izquierda italiana provocada por las repercusiones internacionales del conflicto recién terminado (cap. 3); el período de crítica severa a la política del Estado judío con motivo de la operación "Paz en Galilea" de 1982 (cap. 4); el momento del cambio de perspectiva definitivo, en virtud del cual el "baricentro" del Judaísmo se movió en el pensamiento de Levi desde el territorio concreto del Estado de Israel al territorio inmaterial de la Diáspora (cap. 5).

\section{La identidad judía}

Como es sabido, Primo Levi adquirió conciencia plena de su identidad judía sólo a raíz del conflicto mundial y, sobre todo, de su deportación al campo de exterminio de Auschwitz ${ }^{4}$. De hecho, como el mismo Levi afirmó en diferentes ocasiones, su educación religiosa fue la habitual para un niño judío nacido en la Turín de comienzos de siglo -incluidos dos años de lecciones de doctrina en una Talmud-Torá y la consiguiente admisión en la comunidad judía mediante la ceremonia del Bar Mitzvá celebrada en el mes de agosto de 1932-, pero el judaísmo probablemente no habría significado mucho para él si la proclamación de las leyes raciales de 1938, el estallido de la Segunda Guerra Mundial, la breve experiencia partisana, la detención en el campo de concentración de Carpi-Fòssoli en 1943 y la posterior experiencia de Auschwitz en 1944-1945 no lo hubieran obligado a entrar en contacto con una realidad antes desconocida, in primis la del judaísmo "askenazí" de Europa oriental ${ }^{5}$. En Zinc, el tercer cuento incluido en

\footnotetext{
${ }^{2}$ Quiero expresar aquí mi más sincero agradecimiento a los profesores Bonifacio Bartolomé Herrero, Pablo Carbajosa Pérez, Daniel Ortiz Pereira, Andrea Lellis y Alberto Priego Moreno por la ayuda prestada para la realización de este artículo.

${ }^{3}$ Para una primera aproximación a la figura y a la obra de Primo Levi, cf. la web del Centro internazionale di studi Primo Levi: http://www.primolevi.it/ (agosto 2019). Para la biografía de Levi, cf. Anissimov, Myriam (1996): Primo Levi ou la tragédie d'un optimiste, París, Jean-Claude Lattès (ed. en español 2001: Primo Levi o la tragedia de un optimista (traducción de Teresa Garín Sanz de Bremond), Madrid, Editorial Complutense; Dini, Massimo y Jesurum, Stefano (1992): Primo Levi. Le opere e i giorni, Milán, Rizzoli; Thomson, Ian (2002): Primo Levi. A life, Londres, Hutchinson (ed. norteamericana 2003: Nueva York, Henry Holt and Company; ed. en español 2007: Primo Levi. Una vida (traducción de Julio Paredes), Barcelona, Belacqua; Angier, Carole (2002): The double Bond: Primo Levi. A Biography, Londres, Viking; Belpoliti, Marco (2015): Primo Levi di fronte e di profilo, Milán, Guanda. La edición de referencia de las obras de Levi es la publicada en tres volúmenes a cargo de Marco Belpoliti: cf. Levi, Primo (2016-2018): Opere complete, Turín, Einaudi. Sobre la colaboración de Primo Levi con diferentes periódicos, cf. Rondini, Andrea (2012): Anche il cielo brucia. Primo Levi e il giornalismo, Macerata, Quodlibet. Para la edición española de las obras fundamentales de Levi citadas en el presente artículo, cf. Levi, Primo (2018): Trilogía de Auschwitz (traducción de Pilar Gómez Bedate, introducción de Antonio Muñoz Molina), Barcelona, Península; Levi, Primo (1998): Entrevistas y conversaciones (ed. de Marco Belpoliti, traducción de Francesc Miravitlles), Barcelona, Península; Levi, Primo (2014): El sistema periódico (traducción de Carmen Marín Gaite), Barcelona, Península. Las traducciones que aparecen en el presente artículo son de quien escribe.

${ }^{4}$ Sobre el problema de la identidad de Levi, cf. Harrowitz, Nancy Anne (2017): Primo Levi and the Identity of a Survivor, Toronto-Buffalo-Londres, Toronto University Press, con la bibliografía correspondiente.

5 Véanse las declaraciones de Levi en Edith Bruck: "Ebreo fino a un certo punto" ("Judío hasta cierto punto"), Il Messaggero, 9 de enero de 1975, en Levi, Primo: Opere Complete, III, op. cit., pp. 85-88: "Me han convertido en
} 
el volumen El sistema periódico, publicado en 1975, Levi recuerda con una sonrisa su primera y sorprendida toma de conciencia de una identidad judía:

"[...] soy yo la impureza que hace reaccionar el zinc, soy yo el granito de sal y de mostaza. La impureza, ciertamente: porque precisamente en aquellos meses se iniciaba la publicación de «La Defensa de la Raza», y de pureza se hablaba muchísimo, y yo empezaba a sentirme orgulloso de ser impuro. A decir verdad, hasta precisamente aquellos meses no me había importado mucho ser judío: en mi interior, y en mis contactos con mis amigos cristianos, había considerado siempre mi origen como un hecho casi irrelevante, pero curioso, una pequeña anomalía alegre, como quien tuviera la nariz torcida o pecas en la cara; un judío es alguien que en Navidad no prepara el árbol, que no debería comer salchichón pero que lo come igual, que ha aprendido un poco de hebreo a los trece años y luego lo ha olvidado. Según la revista arriba mencionada, un judío es avaro y astuto: pero yo no era particularmente avaro ni astuto, y tampoco mi padre lo había sido"

Primo Levi, por tanto, fue un judío "a posteriori" ${ }^{7}$, inscrito en la comunidad israelita de Turín, pero no practicante y ni tan siquiera creyente; un judío consciente de pertenecer a una tradición y a una cultura, "italiano por tres cuartas o cuatro quintas partes, según el momento", aunque la parte que quedaba era importante; un judío que sabía que existe una "infinidad de otras culturas, dignas de ser estudiadas y seguidas", incluida la cultura judía, "no muy próspera en Italia, por razones numéricas, entre otras cosas, pero muy próspera en otras partes" y "muy próspera justamente en Europa oriental en la época del estallido de la segunda guerra mundial"; un judío, finalmente, que no tuvo nunca intención de desprenderse de su multiforme identidad de judío integrado ${ }^{8}$.

La "integración”, para un judío, es consecuencia de la Diáspora y fue precisamente en la Diáspora que Levi, como se verá más adelante, vislumbró una vía de salvación para la identidad judía entendida como reflejo de la condición humana, condición contradictoria y, por tanto, digna de una sonrisa que, lejos de ser cínica, puede revelarse como instrumento privilegiado de

judío. [...] Antes de Hitler yo era un chico burgués italiano. La experiencia de las leyes raciales me ha ayudado a reconocer, entre las muchas corrientes del judaísmo, algunas que me gustaban. [...] La independencia espiritual, que había suscitado y guiado las rebeliones de los judíos contra los romanos. También la tradición talmúdica de la discusión apasionada pero precisa, y la de la religión del Libro. Otras corrientes, la religiosa y la mística, me interesaban menos. Este nuevo acercamiento a la tradición ha sido confirmado por la experiencia de Auschwitz, por el contacto con una civilización que no conocía, la del judaísmo "askenazí" de Europa oriental"). A propósito de la influencia de las leyes raciales en su vida, cf. la entrevista concedida a De Rienzo, Giorgio: "In un alambicco quanta poesia”, Famiglia Cristiana, 29 (20 de julio de 1975), en Poliu, Grabriella y Calcagno, Giorgio (eds.) (1992): Echi di una voce perduta. Incontri, interviste e conversazioni con Primo Levi, Milán, Mursia: "Las leyes raciales fueron providenciales para mí, pero también para los demás: ofrecieron la demostración por absurdo de la estupidez del fascismo. El rostro criminal del fascismo (el rostro del delito Matteotti, para entendernos) estaba ya olvidado; quedaba por ver el rostro tonto... En mi familia se aceptaba, con algo de impaciencia, el fascismo. Mi padre se había inscrito en el Partido de mala gana, pero, aun así, se había puesto la camisa negra. Y yo fui "balilla" [niños de 8 a 14 años organizados de forma paramilitar en la "Opera Nazionale Balilla", N.d.T.] y después "avanguardista" [chicos de 14 a 18 años, organizados de forma paramilitar en la "Opera Nazionale Balilla" y, a partir de 1936, en la "Gioventù Italiana del Littorio", N.d.T.]. Podría decir que las leyes raciales me devolvieron, a mí como a los demás, el libre albedrío".

${ }^{6}$ Levi, Primo (2014): Zinco, en Il sistema periodico, Turín, Einaudi, pp. 34-35, en Primo Levi: Opere Complete, I, op. cit., p. 886.

${ }^{7}$ Greer, Germaine: "Talks to Primo Levi”, The Litterary Review, n. 89 (noviembre 1985), pp. 15-19, (con traducción italiana de Erminio Corti) en Levi, Primo: Opere Complete, III, op. cit., pp. 568-577.

${ }^{8}$ Grieco, Giuseppe: "Io e Dio. Non l'ho mai incontrato, neppure nel «Lager»" ("Yo y Dios. No lo he encontrado nunca, ni siquiera en el «Lager»"), Gente, n 48, 9 de diciembre de 1983, en Levi, Primo: Opere Complete, III, op. cit., pp. 385-391; Luce, Dina: "Il suono e la mente" ("El sonido y la mente"), emisión radiofónica del 4 de octubre de 1982, en Levi, Primo: Opere Complete, III, op. cit., pp. 310-320. 
auténtica liberación. Hablando de la jerga usada por sus antepasados, un curioso encaje de vocablos procedentes de la lengua hebraica -la "remota lengua de los padres, sagrada y solemne, geológica, desgastada por los milenios como el lecho de los glaciares"-, y del dialecto piamontés, -“áspero, sobrio y lacónico, nunca escrito, si no por una apuesta"-, Levi afirma:

“[...] este contraste refleja otro, el contraste esencial del hebraísmo de la Diáspora, disperso entre «las gentes» [...], tenso entre la vocación divina y la miseria cotidiana del exilio; y también otro, mucho más general, el contraste ínsito en la condición humana, porque el hombre es un centauro, una maraña de carne y de mente, de aliento divino y de polvo. El pueblo judío, después de la dispersión, ha vivido mucho tiempo y dolorosamente este conflicto y de él ha sacado, al lado de su sabiduría, la risa, que de hecho falta en la Biblia y en los Profetas"9.

\title{
3. Del sueño de Sion a la realidad de Israel: 1935-1968
}

En una entrevista concedida a Fiona Diwan en 1982, Levi expuso su posición acerca del sionismo, a la vez distante y comprensiva:

\begin{abstract}
"Nunca he sido sionista y no lo soy ahora. [...] Sin embargo, no hay que poner en duda el valor histórico del sionismo como verdadera idea-fuerza que consiguió movilizar, arrastrar a las masas extenuadas por la guerra, masas que lo habían perdido todo, no sólo los padres o los hermanos, sino también el techo de una casa a la que pudieran volver. Para un italiano, un francés o un alemán había una casa, una calle, una ciudad a las cuales volver. A ellos les quedaba una identidad concreta. Para un judío, no. Después de lo que había acontecido, habría sido impensable volver atrás. El sionismo fue la esperanza, la vida para muchísimas personas y se configuró como una verdadera migración bíblica. Italia fue el cuello de embudo de esta migración, de este flujo de «desollados» vivos en marcha hacia Palestina"10.
\end{abstract}

La afirmación inicial de Levi, aunque fundamentalmente correcta, necesita ser matizada: en el legado de Levi no es difícil encontrar declaraciones que evidencian un alejamiento progresivo de una imagen juvenil e idealizada de Israel, imagen heredera del sueño bíblico de la Tierra Prometida. El mismo escritor, en una entrevista concedida a Edith Bruck en 1976, confesó su "profunda división" con respecto al Estado judío -división que le impedía expresar un juicio crítico- y admitió que, en los años 1935-40, se había sentido "fascinado por la propaganda sionista", por la promesa de la restauración de una sociedad fundada en la igualdad y en la fraternidad, en "la regeneración por medio del trabajo manual" y "en el rechazo de la propiedad como fundamento de la existencia", y que, durante la Segunda Guerra Mundial, había "aceptado la necesidad de una patria para los judíos de todos los países amenazados por la ocupación nazi", aun admitiendo que, a partir de los años 50, dicha imagen se había ido "gradualmente empañando"11.

\footnotetext{
${ }^{9}$ Levi, Primo (2014): Argon, en Il sistema periodico, Turín, Einaudi, pp. 8-9, en Levi, Primo: Opere Complete, I, op. cit., p. 865.

${ }^{10}$ Diwan, Fiona: "Sono un ebreo, ma non sono mai stato sionista" ("Soy un judío, pero nunca he sido sionista"), Il Corriere Medico (suplemento semanal de Il Corriere della Sera, 3-4 de septiembre de 1982), p. 15, en Levi, Primo: Opere Complete, III, op. cit., pp. 293-297.

${ }^{11}$ Bruck, Edith, op. cit., p. 86: “-Para ti ¿qué representa Israel? Con respecto a Israel me siento profundamente dividido. - iEntonces no soy la única! Río. Ríe él también, después se vuelve más serio y añade: Hasta el punto de impedirme un juicio crítico. En los años 1935-40 me había sentido fascinado por la propaganda sionista, me parecía admirable el país que describían y el futuro que planteaban, la vuelta a la tierra, la restauración de una sociedad fundada en la igualdad y en la fraternidad, la regeneración por medio del trabajo manual, el rechazo de la propiedad como fundamento de la existencia. Más tarde, durante la Segunda Guerra Mundial, había aceptado la necesidad de una patria para los judíos de todos los países amenazados por la ocupación nazi. Sin embargo, debo admitir que, a partir de 1950, esta imagen se ha ido gradualmente empañando".
} 
De hecho, en aquella época, antes de licenciarse cum laude en Químicas en la Universidad de Turín y de retirar el correspondiente título académico provisto de una discriminatoria mención a su "raza judía", Levi entró en contacto con círculos de estudiantes antifascistas y sionistas, tradujo el controvertido "White Paper" con el cual el gobierno británico de Neville Chamberlain había limitado el número de judíos autorizados a quedarse en Palestina y leyó, entre otros muchos libros, "El Estado judío. Ensayo de una solución moderna de la cuestión judía" de Theodor Herzl ${ }^{12}$. Sin embargo, su sionismo no lo llevaría nunca a tomar realmente en consideración la posibilidad de dejar Turín, la ciudad en la que siempre vivió, para empezar una nueva vida en Israel. En el capítulo conclusivo de La tregua, el libro de 1963 que relata la increíble odisea vivida por Levi después de su liberación de Auschwitz, se describe el entusiasmo de un grupo de jóvenes sionistas en viaje hacia la tierra prometida: "se sentían inmensamente libres y fuertes, dueños del mundo y de su propio destino"13. Este encuentro, que, junto con otros factores, inspiraría la publicación de la novela Se non ora, ¿quando? ("Si ahora no, ¿cuándo?") en 1982, tuvo lugar el 15 o el 16 de octubre de 1945. Levi tenía entonces veintiséis años.

La idea de un Israel paradisíaco, aunque ciertamente matizada por el paso de los años, sigue viva en el discurso, titulado Più d'ogni altro paese Israele dovrà vivere ("Más que cualquier otro país, Israel deberá vivir"), que Levi dirigió a la comunidad judía en la sinagoga de Turín el 31 de mayo de 1967, menos de una semana antes de que Israel lanzara el primer ataque de la llamada "Guerra de los Seis Días" contra las tropas de una coalición de estados árabes en cuya primera línea se encontraban Egipto, Jordania, Siria e Irak. Merece la pena recoger integralmente el texto de una intervención en la que vibra con fuerza la angustia renovada de un superviviente que teme las consecuencias de un ataque que, más allá del Estado de Israel, tiene como objetivo las raíces mismas de la humanidad y de su esfuerzo constante por alcanzar una plena convivencia civil ${ }^{14}$ :

"Quisiera volver a lo que dijo anteayer Carlo Casalegno: habló de la juventud israelí,
en cuyos ojos, observó, no se leen ni el miedo ni la angustia. Debo confesarlo: en estos
días ha nacido en mí una angustia profunda. Es una angustia distinta del temor que,
sin embargo, siento, y que creo que cada hombre consciente debería sentir ante la
perspectiva de una guerra: es una angustia que hunde sus raíces profundamente en
recuerdos nunca desaparecidos de lugares que no deben volver a existir, de
experiencias y violencias que esperábamos borradas de la historia de la civilización;
sin embargo, a estos recuerdos se sobreponen palabras recientes, que también
creíamos extinguidas. Se trata de un lenguaje absurdo y salvaje, no nuevo:
«venceremos con la ayuda de Dios, y exterminaremos a nuestros enemigos». No sería
capaz de imaginar una blasfemia peor: en las tablas que tengo a mis espaldas está
escrito: «No pronunciarás en vano el nombre de Dios», pero esto es mucho peor que

12 Thomson, Ian: op. cit., pp. 95-96 de la ed. norteamericana.

${ }^{13}$ Levi, Primo (2014): La tregua, Turín, Einaudi, p. 198, en Levi, Primo: Opere Complete, I, op. cit., p. 468: “Si sentivano immensamente liberi e forti, padroni del mondo e del loro destino". Acerca de las operaciones de emigración clandestina organizadas por la Haganá en Italia, cf. Sereni, Ada (1973): I clandestini del mare. L'emigrazione ebraica in terra d'Israele dal 1945 al 1948, Milán, Mursia, cit. en Speelman, Raniero: "Primo Levi, Giorgio Pressburger e Israele", en Speelman, Raniero; Tonello, Elisabetta y Gaiga, Silvia (eds.) (2014): Atti del convegno Ricercare le radici: Primo Levi lettore - Lettori di Primo Levi. Nuovi studi su Primo Levi, (colección Italianistica Ultraiectina. Studies in Italian Language and Culture, 8), Utrecht, Igitur Publishing, pp. 225-236.

${ }^{14}$ En los días inmediatamente anteriores a la guerra y durante los pocos días que duró el conflicto, Levi participó en diferentes acciones de solidaridad a favor del pueblo israelí. Cf. Levi, Primo: "Migliaia di cittadini partecipano alla manifestazione per Israele" ("Miles de ciudadanos participan en la manifestación a favor de Israel"), $L a$ Stampa, 1 de junio de 1967, p. 2; Id., "Una città solidale con Israele" ("Una ciudad solidaria con Israel”), La Stampa, 7 de junio de 1967, p. 6. 
pronunciarlo en vano, es invocar su ayuda para una masacre. ¿Todavía hay, en el mundo, quien cree en la guerra santa, y la identifica con la guerra total? Sabe el cielo cuánto amamos nosotros la paz: todos, quiero decir, pero especialmente nosotros que hemos sufrido el aspecto más repugnante de la guerra total, el campo de exterminio. Sabe el cielo cuán profundamente comprendemos nosotros que la paz presupone la tolerancia, es la tolerancia: cuánto la hemos predicado, y apoyado, y practicado en la medida en que nos ha sido posible, para que al justo no se le atribuyeran los cargos del impío. Como consecuencia, puesto que para nosotros es un honor, es más, una necesidad vital, sentirnos en lo justo y en lo honrado, hemos intentado con todas nuestras fuerzas no ceder a lo que el sentimiento obviamente nos sugería, hemos intentado juzgar desde lo alto, desde la barrera. Esto no ha sido fácil: las relaciones de cada judío, aunque no sea sionista, con Israel son evidentes y profundas. ¿Debo atreverme a decir que igualmente evidentes y profundas son también las de cada cristiano, mejor dicho, de cualquier hombre civilizado? Me gustaría poder contestar que sí: me gustaría saber que todos ven a Israel como lo vemos nosotros, como un pequeño país nacido de la persecución y de la matanza, garantía y señal de que no habrá más persecuciones ni matanzas: como país socialista, heredero de tradiciones antiguas y modernas, en busca de un equilibrio difícil, pero abierto al diálogo político, receptivo a todas las opiniones, incluidas las que nos repugnan: como país creado de la nada, gracias al trabajo, como «la tierra», la tierra por excelencia, a la cual se «sube» para construirla y para ser construidos por ella; finalmente, como país del regreso, único e insustituible, como país de la Biblia, en el cual cada colina, cada camino nos devuelve en espíritu a las generaciones que nos han precedido. Hemos, pues, intentado, nos hemos esforzado por no ceder al sentimiento, por sepultar en nosotros, por acallar estos vínculos, por así decirlo personales, que nos unen con Israel. ¿Qué queda? ¿Qué subsiste para confirmarnos en nuestro sentimiento de solidaridad? Estoy convencido de que algo subiste, y no poco, sino mucho: subsisten algunas consideraciones que me parecen universales y fundamentales, y por las cuales Israel debe vivir. Israel debe vivir, en primer lugar, porque debe vivir cada país, y porque debe vivir cada hombre. Como no existe una culpa por la cual un hombre deba ser asesinado, no existe así situación política en la que un país deba ser destruido, y un pueblo deba ser exterminado. Que no se nos hable de retorsión: la existencia de Israel puede ser incómoda para algunos, puede perjudicar algún prestigio, pero no amenaza a nadie; si existe en el mundo un pueblo que tiene sobre su conciencia millones de tumbas, ese pueblo no somos nosotros. Israel no amenaza a nadie, además, por las mismas razones por las cuales Finlandia no amenaza a la Unión Soviética y Albania no ha amenazado nunca a Italia, a saber, porque se encuentra en condiciones de enorme inferioridad numérica, y no está gobernado por locos. Israel por tanto debe vivir, porque tiene derecho a vivir como cualquier otro país: sin embargo, no es un país como los demás. Es un país que tiene la espalda contra la pared, en el aspecto geográfico y en el aspecto espiritual. No se le está pidiendo renunciar a una provincia, o abandonar una estructura política, o romper una alianza: se le está pidiendo simplemente dejar de existir. Tal vez (digo tal vez) se trate más de un grito de guerra que de un propósito meditado, pero todos deben comprender que, para Israel y para nosotros, estas palabras tienen un sonido siniestro: en años no lejanos esta amenaza ha sido formulada durante mucho tiempo y luego ejecutada, lentamente, metódicamente, sin remisiones y sin piedad. Todos deben recordar que la generación que ha creado Israel está formada enteramente por supervivientes de la masacre del judaísmo europeo: ésta no es una figura retórica ni una exageración, sino una verdad literal, hombre a hombre. Los pioneros del sionismo son los supervivientes de los 
pogromos zaristas, de los guetos, de las fosas comunes, de los "lager" hitlerianos. Por esto, decía, Israel no es un país como los demás: es un país respecto al cual el mundo entero es deudor, es un país de testigos y de mártires; es también el país de los insurrectos de Varsovia, de Sobibor y de Treblinka. Si es delictivo hablar de «arrasar» Florencia $^{15}$, o cualquier otro país, doblemente delictivo es el propósito de infligir dispersión y masacre a los supervivientes de la dispersión y de la masacre: y no sentiríamos en absoluto que algún nuevo gibelino, sin dejar por esto de ser gibelino, expresara, a propósito de este punto, su pensamiento a cara descubierta. De hecho, quizá más que la intransigencia de los árabes, que no comprendemos del todo, pero que ciertamente están implicados en el conflicto, nos resultan dolorosas la intransigencia y la aquiescencia apresurada de algunos de sus improvisados aliados. En su repetir mecánicamente fórmulas rígidas y juicios prefabricados, tememos distinguir un mal antiguo que en tiempos recientes ha causado muchos daños, es decir, la costumbre de obedecer sin discutir, de decir siempre que sí, de delegar en otros el derecho humano a construirse una opinión. Se trata de servilismo y de anestesia moral, que, a la larga, han llevado a más de uno ante el tribunal de Núremberg y más allá. Sí, Israel es actualmente un aliado de los Estados Unidos o bien, empleando precisamente una fórmula rígida, es definido como un peón del imperialismo. Esto es embarazoso y no les gusta a todos, ni en Israel ni aquí: es más, gusta tanto menos cuanto más se deteriora el prestigio de los Estados Unidos en la fea aventura del Extremo Oriente, y desafortunadamente tiende a hacer olvidar que, al contrario, Israel nació precisamente en sentido antiimperialista, aprovechando y acelerando el derrumbamiento del colonialismo británico. ¿Es ésta una alianza determinante, una alianza que obliga? No creo: la Constitución israelí me parece asentada sólidamente sobre bases socialistas y democráticas, el interés del gobierno se dirige mucho más a las cuestiones internas que a la política de potencia, como, por otra parte, es natural para un pequeño país; además, finalmente, si toda alianza tuviera que obligar, ¿acaso no ha habido otros grandes países aliados de los Estados Unidos de América que no se han contagiado? Sí, la guerra, se dirá: pero ¿acaso Israel no está en estado de guerra? Sin embargo, existe otra razón, diré que específica, por la cual Israel tiene derecho a la vida; y no sólo a la vida, sino también a la amistad y al aprecio de la humanidad entera. Nosotros, la especie humana, nosotros los hombres, quizá solos en el universo, a través de una historia cien veces milenaria y llena de errores y de dolores, estamos llevando a cabo una gran obra, que es la de la conquista pacífica de la naturaleza y de la victoria contra el hambre, el sufrimiento, la necesidad y el miedo. No podemos llevarla a cabo divididos: cada guerra, incluso local, cada discordia, nos aleja de la meta y nos hace perder un terreno conquistado con gran esfuerzo: la humanidad será una, o no será. Pues bien, me atrevo a proponeros interpretar en este espíritu la historia de Israel, es decir como compendio y símbolo de la historia de la humanidad, del mismo modo que en el desarrollo de cada germen se reconocen el compendio y el símbolo de la especie de la que el germen ha brotado. En la inmensa historia de la humanidad, y en la breve historia de Israel, se leen las virtudes y la vocación de la especie humana: en ella se reconoce la superación de la dispersión, de la discordia, de los sufrimientos por lengua, origen, raza, y su fusión, antes extenuante, luego fácil, en una convivencia civil. En ella se encuentran la construcción de un Estado y la restitución de una ley que es obra de valor, inteligencia, fantasía y piedad: en una palabra, es obra humana. En ella se encuentran la conquista del desierto, la transformación de la naturaleza de enemiga en amiga, en lo que consiste la más alta vocación de la ciencia, y la

\footnotetext{
${ }^{15}$ Referencia a Alighieri, Dante: Comedia, X, 92 y al personaje de Farinata degli Uberti, noble gibelino sienés que se opuso a la destrucción de Florencia después de la victoria en la batalla de Montaperti en 1260.
} 
esencialidad de ésta en el destino del hombre: y de hecho quizá no exista en el mundo entero un país en el cual el contacto entre el hombre y los árboles sea más íntimo y más fructífero que en Israel. Y no hay que creer que para llevar a cabo esta redención de la tierra sea suficiente el dinero: con el dinero se pueden hacer infinitas cosas, se puede corromper, se pueden fabricar cañones; se puede derrochar a mares, como sucede en otros lugares, pero no se construye nada bueno si falta buena voluntad. Nosotros no quisiéramos, nosotros no queremos, que este rincón de tierra tan penosamente creado de la nada sea destruido. No lo será: pero si lo fuera, moriría junto con él una porción de humanidad mucho más grande de lo que los números desnudos llevan a pensar. Por encima de las facciones y del cínico juego político, por encima del dinero y del petróleo, la Tierra de Israel es una idea, y las ideas son preciosas y pocas: no deben y no pueden ser suprimidas". ${ }^{16}$

Como han señalado diversos estudiosos, en el texto de Levi se perciben ecos de la propaganda sionista y se formulan juicios inexactos, aunque comprensibles a la luz de la urgencia del momento ${ }^{17}$. De hecho, Israel no se creó "de la nada": su nacimiento se enmarcó en el contexto del mandato británico de Palestina, implicando la llamada Nabka, es decir el desplazamiento obligatorio de la población autóctona como consecuencia de la guerra árabe-israelí de 1948, y su clase dirigente, lejos de regirse por modelos socialistas, programó la exclusión sistemática de la mano de obra árabe y la explotación económica de los mizrajím, es decir de los judíos procedentes de territorios árabes. Levi no hace referencia alguna a la necesidad de definir de una vez por todas los confines geográficos de Israel y no pone nunca en duda el carácter democrático de la organización estatal israelí, aunque admita, de una manera un tanto contradictoria, su incomodidad ante la evidencia del poderoso vínculo que une Israel con unos Estados Unidos implicados en la "fea aventura" de Vietnam. Finalmente, con su llamamiento a la unicidad de Israel en cuanto estado nacido de la sangre de millones de seres humanos, Levi corre el riesgo de usar la Shoah como clave interpretativa del conflicto árabe-israelí. En palabras de Stefano Bellin, "semejante representación imaginaria ignora descaradamente la expropiación de las tierras palestinas (con la consiguiente destrucción de cultivos y desarraigo de árboles), el borrado intencional de sitios arqueológicos árabes y de toda herencia histórica, la negación ontológica del pueblo palestino (resumida en la infame afirmación de Golda Meir según la cual los palestinos no existían), la cuestión de los refugiados y la sistemática discriminación de los judíos palestinos en el «Estado democrático judío»"18.

\footnotetext{
${ }^{16}$ Levi, Primo: "Più che ogni altro paese, Israele dovrà vivere" ("Más que cualquier otro país, Israel deberá vivir”), Resistenza. Giustizia e Libertà, XXI, n. 7 (7 de julio de 1967), p. 5, en Levi, Primo: Opere complete, II, op. cit., pp. 1350-1353.

${ }^{17}$ Scarantino, Sergio: "Il dibattito storiografico sulla guerra dei Sei giorni”, Studi Storici, año 49, n. 1 (enero-marzo 2008), pp. 135-175. Cf. también Bellin, Stefano: "The wound and the hope: Primo Levi's troubled relationship with Israel”, Nemla Italian Studies Special Issue: The Jewish Experience in Contemporary Italy, ${ }^{\circ} 37$ (2015), pp. 71-96. Bellin cita, entre otras fuentes, Vidal-Naquet, Pierre (1981): Les Juifs, la mémoire et le présent, París, Maspero (ed. en español 1996: Los Judios, la memoria y el presente (traducción de Daniel Zadunaisky), México, Fondo de Cultura Económica; Zertal, Idith (1998): From Catastrophe to Power: Holocaust Survivors and the Emergence of Israel, Londres, University of California Press; Zertal, Idith (2005): Israel's Holocaust and the Politics of Nationhood (trans. by Chaya Galai), Cambridge, Cambridge University Press (ed. española 2010: La nación y la muerte: la shoá en el discurso y la política de Israel (traducción de Marta Pino Moreno), Madrid, Gredos); Zertal, Idith y Eldar, Akiva (2013): Les seigneurs de la terre. Histoire de la colonisation israélienne des territoires occupés, París, Seuil.

${ }^{18}$ Bellin, Stefano, op. cit., p. 80. A propósito de la presencia árabe en Palestina antes de la fundación del estado de Israel, cf. lo declarado por Levi en Camon, Ferdinando (2014): Conversazione con Primo Levi, Milán, Gruppo Editoriale Mauri Spagnol, en Levi, Primo: Opere Complete, III, op. cit., pp. 830-858 (cf. p. 851): “[El estado de Israel] habría tenido que ser una balsa salvavidas, el santuario al que habrían podido acudir los judíos amenazados en los demás países. La idea de los padres fundadores era ésta, y era anterior a la tragedia nazi: la tragedia nazi la ha multiplicado por mil. Ya no podía faltar aquel país de la salvación. Al hecho de que hubiera árabes en aquel
} 
Demostrando de manera clamorosa lo infundado de todos los temores, en sólo seis días, del 5 al 10 de junio, el Tsahal israelí ganó la guerra, conquistando para Israel un territorio que, violando las leyes internacionales, incluía los Altos del Golán, Cisjordania, con la parte oriental de Jerusalén y la Ciudad Vieja, y la Franja de Gaza. La extraordinaria exhibición de poderío militar y el consiguiente vuelco de la situación geopolítica no dejaron indiferente a Levi que, en una carta dirigida a Hety Schmitt-Maßß, expresó con suficiente claridad su desilusión por un Israel convertido en un "país como cualquier otro", bueno para luchar y propenso al orgullo nacional ${ }^{19}$ :

Por lo que a mí respecta, he sentido, en este orden: una creciente angustia antes de que la situación se precipitara rápidamente; vergüenza, sí, la vergüenza de Auschwitz, ante mis hijos, por haberlos engendrado en un mundo sobre el cual la guerra se cierne de forma estable; finalmente, un poco de alivio, al tener las primeras noticias del éxito militar de los israelíes. [...] Ésta no es la Tierra Prometida con la que habíamos soñado. Tal vez sea ésta una ingenuidad absoluta, semejantes Tierras no existen en la tierra: pero Israel, desde sus comienzos, nos tenía acostumbrados a milagros tan grandes que nosotros esperábamos que pudiera hacer lo mejor, cumplir el único milagro verdadero, el de establecer la paz permanente con sus vecinos. ${ }^{20}$

Quizá para poder comprobar personalmente la veracidad de sus ideas, Levi decidió visitar Israel, por primera y única vez en su vida, en la primavera de 1968, a poco menos de un año del final de la guerra. La visita, llevada a cabo junto con un grupo de cuarenta ex partisanos del grupo Giustizia e libertà, dejó en el escritor una sensación agridulce. En un artículo titulado Gli incontri nei Kibutz ("Los encuentros en los kibutz"), Levi, aun elogiando el espíritu que anima estas comunidades agrícolas de gestión colectiva en las que llega a cumplimiento "la utopía" de una democracia pacífica, y aun reivindicando con claridad el derecho de Israel a existir más allá de los errores cometidos, denunció con claridad triste que "Israel no es Europa". Quizá pueda considerarse éste como el punto de inflexión de su visión del Estado judío.

"La sensación y los recuerdos de quien viaja se pueden enmarcar en dos esquemas de referencia: el de la comparación con el país de uno y el de la comparación con la imagen que uno tenía del país al que ha viajado. Había leído y oído muchas cosas acerca de Israel, desde el tiempo (hace más de treinta años) en que los primeros «mensajeros» sionistas habían llegado a Italia: me había construido una imagen de él y, ante el país real, esta imagen me ha resultado desenfocada y esquemática. Pensaba en Israel como en un rincón de Europa, es más, de Occidente, engastado en el mundo oriental. No es así, o es así en una medida muy pequeña. Israel no es Europa: heredero de todas las corrientes de pensamiento europeas, Israel carece notablemente de aquel poso histórico que unifica Europa desde Gibraltar hasta los Urales y que constituye el esqueleto de todos sus núcleos urbanos: falta aquí la «mediana edad» que domina en París, en Berlín, en Praga; todo es novísimo (y a menudo precario) o bien antiguo más allá de cualquier medida, de una antigüedad en la que la historia y la obra humana se desvanecen en la geología. Veinte años después de su constitución como Estado y después de sesenta o setenta después del primer verbo sionista, Israel sigue siendo un

país nadie lo pensaba. A decir verdad, no había muchos. Y se consideraba como un hecho irrelevante, antes esta gigantesca vis a tergo, que empujaba a los judíos de toda Europa".

${ }_{19}$ Thomson, Ian, op. cit., p. 311 de la ed. norteamericana.

${ }^{20}$ Belpoliti, Marco: "Primo Levi, Auschwitz, la Liberazione: il carteggio inedito" ("Primo Levi, Auschwitz, la Liberación: el epistolario inédito"), L'Espresso, 10 de abril de 2017. Acerca de la correspondencia entre Levi y Schmitt-Maaß, conservada en el Stadtarchiv de Wiesbaden, cf. Thomson, Ian: "Primo Levi's Correspondence with Hety Schmitt-Maas", en Pugliese, Stanislao G. (2011): Primo Levi's Science and Humanism after the Fall, Nueva York, Fordham University Press. 
país de pioneros, es decir, de gente concreta, resuelta y espartana, que mira a lo sólido y no hace mucho caso de las formas. En él no se encuentra el arte de vivir, sino el de construir, del ayudar a crecer: la nobleza y el alma de Israel tienen dos centros, evidentes también para el viajero apresurado, el plantar árboles y el criar niños. A los extranjeros se les presentan tanto los unos como los otros, con el orgullo sincero y solemne del artesano: «Esto es obra de mis manos». Sin embargo, los árboles y los niños representan el futuro, y en Israel, país recién nacido, el sentimiento del futuro está vivo en todas las conciencias, mucho más que el sentimiento del pasado. El pasado de Israel, como es sabido, es un patrimonio ilustre y único en el mundo; la prehistoria, la Biblia y el Evangelio vienen hacia ti a cada paso, en cada rincón del país, con sugestión y poesía profunda. El aliento bíblico impregnaba el pensamiento de los grandes profetas del sionismo, pero hoy el acento cae en otro lugar; este país jovencísimo no puede permitirse todavía muchos lujos, y vivir en un aura de mitos es un lujo. Israel nació y ha crecido en medio de problemas espantosos, externos e internos: desde los pogromos y desde los "lager" hasta la redención de la tierra, ha recorrido un camino increíblemente duro, que tenía como apuesta la supervivencia. A veces se ha equivocado, quizás esté todavía equivocándose, pero ya tiene tablas, y existe, y tiene derecho a existir. Por esto el acento cae hoy en los problemas de hoy: las superestructuras, lo bello, lo dulce, lo cómodo, llegarán más tarde, cuando el andamiaje se haya afianzado, las fronteras sean seguras, los prófugos hayan encontrado su sitio y las cien razas se hayan fusionado. Desafortunadamente, no han sido muchas las ocasiones para hablar con tranquilidad con la gente de la calle, con los trabajadores, con los niños, con los soldados, con las mujeres, con los variados ejemplares del asombroso mosaico de gentes que puebla Israel: sin embargo, cada encuentro ha sido memorable. Como en las estructuras, así en las conciencias, éste es un país joven y por tanto dinámico, sencillo, enérgico e intemperante: la confianza en sí mismos y en el Estado, la identificación con el Estado, estas virtudes cívicas tan debilitadas en Italia y en Europa, tan profundamente sepultadas por nuestro secular escepticismo político, por nuestra desesperación moral, resplandecen aquí en la luz del primer día. Las fronteras distan un paso, en cada familia hay un soldado, todos están comprometidos: las decisiones del Gobierno son aprobadas o discutidas, incluso acerbamente, pero nunca ridiculizadas ni cubiertas con la arena de la indiferencia; se imprimen, y se leen, ávidamente, al menos siete diarios. ¿Adónde ha ido a parar el espíritu sutil, alegre-triste, atormentado, cerebral, del judaísmo centroeuropeo, fermento de la civilización occidental? En los ojos serios, claros, de mirada recta de las nuevas generaciones no hay vestigio alguno de él: una generación más y será imposible (además de inútil) establecer si tu interlocutor procede de los bosques de Volinia, o del gueto de Roma, o del puerto de Salónica, o de los altiplanos desiertos del Yemen. Memorables entre todos los encuentros, los tenidos en los kibutz. Su peso numérico en el país se ha reducido, debido principalmente al rápido aumento de la población en el último decenio: hoy en día, viven en los kibutz no más de cien mil personas. El propósito de conformar el país entero según el modelo colectivista se ha demostrado vano, lo que no puede sorprender, pero el espíritu de los primeros pioneros, igualitarios y tolstoyanos, sobrevive incontaminado. Ha superado la prueba más peligrosa, que es la de la prosperidad: en la mayoría de los kibutz se vive hoy sin graves problemas colectivos, y sin ningún problema individual, puesto que la colectividad, apoyada por el Estado, provee todas las necesidades dentro de unos amplios límites. Sin embargo, no hay síntomas de involución: el cuidado con el que se evita la instauración de una clase dominante es siempre igualmente meticuloso, la rotación de los cargos se respeta de manera rigurosa, también al precio de un menor 
rendimiento del trabajo, la paridad de derechos no admite excepciones. Si el peso numérico del kibutz se ha visto reducido, el peso moral permanece altísimo: los trabajadores del kibutz constituyen la aristocracia intelectual, técnica y espiritual de Israel, son estimados por todos y no tienen enemigos. Se respira en el kibutz una atmósfera severa y serena al mismo tiempo, de alegría y de compromiso. Se respiran el microcosmos y la utopía: sin embargo, se trata de una utopía, tal vez la única, que se ha realizado, que se alimenta de sí misma desde hace ya muchos decenios, que ha dado frutos y no ha provocado víctimas". ${ }^{21}$

El kibutz representa para Levi la verdadera y única materialización del espíritu de los pioneros, habiendo perdido el Estado israelí en su conjunto el impulso inicial de igualitarismo y universalidad. Una vez más, Levi parece olvidar las desigualdades estructurales que caracterizan a la sociedad israelí y "el hecho de que incluso antes de que el Estado de Israel naciera (y naturalmente después), los árabes no fueron nunca admitidos como miembros del mismo, que la mano de obra barata (árabe o judía oriental) es esencial para el funcionamiento de los kibutz, que los kibutz "socialistas" se han establecido en tierras confiscadas a los árabes"22. Aun así, el artículo demuestra con claridad que Levi estaba empezando a tomar definitiva conciencia de la necesidad de "enfocar" mejor su punto de vista acerca de Israel. En este sentido, la alusión relativa al hecho de que los kibutz no han "provocado víctimas" puede leerse como una crítica no demasiado velada al desplazamiento de la política del Estado judío hacia la derecha militarista.

\section{Las dificultades de la izquierda italiana: 1968-1982}

El resultado de la "Guerra de los Seis Días" complicó notablemente la situación en el tablero internacional: por un lado, la entrada en el gobierno de unidad nacional israelí de un hombre como Menájem Beguín en calidad de ministro sin cartera significó la aparición en el ejecutivo de una derecha nacionalista muy próxima al judaísmo conservador y el consiguiente fortalecimiento de las posiciones del panarabismo; por el otro, la derrota de la coalición árabe representó un duro golpe para la Unión Soviética, que había apoyado la política de Nasser desde la construcción de la presa de Asuán, con la esperanza de llegar a controlar cómodamente las reservas petrolíferas de los territorios árabes, y determinó no sólo la ruptura de las relaciones diplomáticas entre Israel y los países del "bloque soviético", sino también el alejamiento por parte de los principales partidos de la izquierda europea de las políticas del Estado judío, con el relativo acercamiento de los mismos a las razones del mundo árabe.

En Italia, la relaciones entre comunistas, socialistas y judíos durante la guerra y la inmediata postguerra fueron en general excelentes ${ }^{23}$ : la idea de Israel como un país en el cual, mediante la experiencia del kibutz, el socialismo había encontrado una posibilidad concreta de vida, indujo a los dirigentes de los principales partidos de izquierda a apoyar la emigración a Palestina desde puertos italianos. Sin embargo, a partir de 1953, es decir de la época del llamado "complot de los médicos", un juicio contra unos profesionales sanitarios judíos acusados de conspirar contra el régimen de Stalin que representó el primer y último acto de una campaña antisemita interrumpida sólo por la muerte del dictador, y del atentado del 9 de febrero contra la delegación soviética en Tel Aviv que llevó a la ruptura de las relaciones diplomáticas entre

\footnotetext{
${ }^{21}$ Levi, Primo: "Gli incontri nei Kibutz" ("Los encuentros en los kibutz”), Resistenza. Giustizia e libertà, XXII, no 4 (abril 1968), p. 7, en Levi, Primo: Opere complete, II, op. cit., pp. 1354-1356.

${ }^{22}$ Said, Edward W. (1992): The Question of Palestine, Nueva York, Vintage, p. 21, cit. en Bellin, Stefano, op. cit., pp. 82-83.

${ }^{23}$ Sobre las relaciones entre los partidos de la izquierda italiana y el Estado de Israel, cf. Molinari, Maurizio (1995): La sinistra e gli ebrei in Italia, 1967-1993, Milán, Corbaccio; Di Figlia, Matteo (2012): Israele e la sinistra: gli ebrei nel dibattito pubblico italiano dal 1945 a oggi, Roma, Donzelli; Brillanti, Claudio (2018): Le sinistre italiane e il conflitto arabo-israeliano-palestinese: 1948-1973, Roma, Sapienza Università Editrice.
} 
Israel y la Unión Soviética, diarios como L'Unità, órgano del PCI (Partido Comunista Italiano), empezaron a publicar artículos claramente hostiles a las posiciones de Israel ${ }^{24}$. Naturalmente, no faltaron en el país transalpino voces contrarias a esta lectura filo-soviética de los acontecimientos. También en 1956, con ocasión de la "Guerra del Sinấ", la izquierda italiana, con la excepción de algunos representantes de primer nivel del PRI (Partido Republicano Italiano), se alineó con la Unión Soviética del lado del Egipto de Nasser contra la coalición formada por Israel, Reino Unido y Francia. De esta manera, cuando estalló la "Guerra de los Seis Días", entre los representantes de la izquierda italiana, sólo la corriente mayoritaria del PSI (Partido Socialista Italiano), encabezada por su presidente Pietro Nenni, el Partido Radical de Marco Pannella y algunos intelectuales como Pier Paolo Pasolini se pusieron del lado de Israel $^{25}$. La posición de Levi en 1968, en este sentido, con todas las matizaciones necesarias, iba muy lentamente acercándose a la de la corriente mayoritaria del PCI.

A partir de 1968, las relaciones entre Israel y la izquierda italiana, con la excepción de Pietro Nenni (PSI), del grupo dirigente del PRI y del Partido Radical de Marco Pannella, fueron empeorando progresivamente. "La izquierda, casi en su totalidad, abrazó la causa palestina. La izquierda extraparlamentaria, en aquella época muy influyente, apoyó la línea de los fedayines más radicales" 26 . Ante acontecimientos como el atentado de "Septiembre Negro", organización terrorista palestina, contra los atletas israelíes en las Olimpiadas de Múnich de 1972, o la llamada "Guerra del Yom Kipur", en octubre del año siguiente, la solidaridad de la izquierda italiana fue en general escasa: "para la izquierda, casi todos los israelíes debían ser criticados sin falta y a los judíos les tocaba la extravagante (¿extravagante?) tarea de recitar públicamente el «mea culpa» por todo lo que se decidía en Jerusalén y en Tel Aviv"27.

\footnotetext{
${ }^{24}$ Véase., como ejemplo significativo, el breve artículo anónimo titulado "Il governo d'Israele attaccato in Parlamento" ("El Gobierno de Israel atacado en el Parlamento”), publicado en L'Unità, 17 de febrero de 1953 (p. 6). Comentando la intervención con la cual el primer ministro israelí Ben Gurión había intentado "descargar a la policía israelí y al gobierno israelí de sus responsabilidades con respecto al provocador atentado contra la delegación soviética de Tel Aviv", el autor afirmaba que "Así (Ben Gurión) se erigió en defensor de los médicos asesinos detenidos en la URSS, esforzándose por presentar a los criminales al servicio de las organizaciones de espionaje sionistas como víctimas de una «persecución antisemita»".

${ }^{25}$ Véanse las consideraciones lúcidas de Pier Paolo Pasolini: "Israele" ("Israel”), Nuovi Argomenti, Nuova Serie n. 6 (abril-junio de 1967): “Ahora, en estos días, leyendo «L'Unità», he sentido el mismo dolor que se siente al leer el más mentiroso de los diarios burgueses. ¿Cómo es posible que los comunistas hayan elegido de forma tan tajante? ¿No era acaso ésta, por fin, una buena ocasión para “elegir con dudas”, que es la única manera humana de elegir? El lector de «L'Unità» ¿no habría [...] pensado por fin -y es lo mínimo que podría hacer- que nada en el mundo se puede partir en dos? ¿Y que él mismo está llamado a decidir sobre su propia opinión? ¿Y por qué, en cambio, «L’Unità» ha llevado a cabo una auténtica campaña para «crear» una opinión? ¿Tal vez porque Israel es un Estado mal nacido? Pero ¿qué Estado, ahora libre y soberano, no ha nacido mal? ¿Y quién de nosotros, además, podría garantizarles a los judíos que en Occidente no habrá jamás otro Hitler o que en Estados Unidos no habrá nuevos campos de concentración para drogadictos, homosexuales y... judíos? ¿O que los judíos podrán vivir en paz en los países árabes? ¿Acaso pueden garantizar esto el director de «L’Unità» [...] o cualquier otro intelectual comunista? ¿Y no es lógico que quien no puede garantizar esto acepte, por lo menos en su corazón, el experimento del Estado de Israel, reconociendo su soberanía y su libertad? ¿Y qué ayuda se presta al mundo árabe fingiendo ignorar su voluntad de destruir Israel, es decir, fingiendo ignorar su realidad? ¿No saben todos que la realidad del mundo árabe, así como la realidad de la mayoría de los países en vías de desarrollo -incluida, en parte, Italiatiene clases dirigentes, policías y magistraturas indignas? ¿Y no saben todos que, igual que hay que distinguir a la nación israelí de la estupidez del sionismo, así hay que distinguir a los pueblos árabes de la irresponsabilidad de su fanático nacionalismo? La única forma de ser amigos de los pueblos árabes en este momento, ¿no es quizá ayudándolos a comprender la política alocada de Nasser, que, no digo la historia, sino el más elemental sentido común, ha juzgado y condenado ya?").

${ }^{26}$ Mieli, Paolo: "E gli ebrei rifiutarono il ricatto antisionista" ("Y los judíos rechazaron el chantaje antisionista"), Corriere della Sera, 15 de mayo de 2012, p. 38, en Mieli, Paolo (2017): Il caos italiano. Alle radici del nostro dissesto, Milán, Rizzoli.

${ }^{27}$ Ibid.
} 
A lo largo de los años setenta, Primo Levi intervino muchas veces en el debate público relativo al problema del terrorismo nacional e internacional, llegando a expresar, en algunos casos, juicios sorprendentemente duros ${ }^{28}$. Sin embargo, en su legado de aquella época no se encuentran muchas declaraciones acerca del estado de Israel ${ }^{29}$, a propósito del cual Levi tiene la impresión de que "tienda, como por otro lado es justo que suceda, a transformarse en un país de Oriente Medio y, por tanto, a cercenar sus vínculos con la cultura occidental en general" 30 .

\section{La “Guerra del Líbano” y los límites del Estado judío: 1982-1983}

El 3 de junio de 1982, sicarios de una organización terrorista encabezada por el palestino Abu Nidal intentaron asesinar en Londres al embajador israelí Shlomo Argov, dejándolo paralítico. Tres días más tarde, el gobierno israelí, con Menájem Beguín como Primer ministro y Ariel Sharón como ministro de Defensa, dio comienzo a la "Operación Paz en Galilea", invadiendo el sur del Líbano con el propósito de atacar las bases que la Organización para la Liberación de Palestina (OLP) tenía en aquel territorio, crear una zona de seguridad en la frontera septentrional de Israel, reducir la presencia militar siria y establecer en Beirut un gobierno favorable a los intereses israelíes. El episodio más oscuro del conflicto fue la masacre del 18 de septiembre de 1982 en la que perdieron la vida cientos de civiles palestinos residentes en el barrio de Sabra y en el campo de refugiados de Chatila, en la periferia de Beirut. Esta acción, llevada a cabo por miembros de la Falange Libanesa, en su mayoría pertenecientes a la iglesia cristiana maronita, fue condenada el 16 de diciembre del mismo año por la Asamblea General de las Naciones Unidas, que la calificó como "acto de genocidio" "31. El 8 de febrero de 1983, el informe de la Comisión Cahan, instituida el 28 de septiembre del año anterior para aclarar lo sucedido, aun confirmando la responsabilidad directa de los falangistas libaneses, reconoció las "responsabilidades indirectas" de diferentes altos cargos del Estado israelí, entre los cuales se encontraban los citados Beguín ("for not exercising greater involvement and awareness in the matter of introducing the Phalangists into the camps") y Sharón (" for ignoring the danger of bloodshed and revenge when he approved the entry of the Phalangists into the camps as well as not taking appropriate measures to prevent bloodshed"), recomendando la dimisión del mismo Sharón y la destitución del cargo de Director de la Inteligencia militar del Mayor General Yehoshua Saguy, así como de otras autoridades ${ }^{32}$.

Ante los acontecimientos de la "Guerra del Líbano", Primo Levi pareció perder la paciencia: en pocos meses, firmó un manifiesto para reivindicar la retirada de las tropas israelíes y publicó diferentes artículos en diarios y periódicos, sobre todo en La Stampa y en La Repubblica. Los argumentos esgrimidos por Levi no dejaron indiferentes ni al mundo judío ni a la opinión pública italiana e internacional.

El 16 de junio de 1982, diez días después del estallido del conflicto, en la parte superior derecha de la página 10 de La Repubblica, apareció un texto titulado Perché Israele si ritiri

\footnotetext{
${ }^{28}$ Cf., por ejemplo, lo que Levi declaró en una entrevista concedida a Virgilio Lo Presti: “Tornare, mangiare, raccontare" ("Volver, comer, narrar"), Lotta Continua (18 de junio de 1979), en Levi, Primo: Opere Complete, III, op. cit., pp. 158-164: (p. 161) "cuando se quemaban las sedes del MSI [Movimiento Sociale Italiano, fundado en 1946 por miembros de las desaparecidas organizaciones fascistas, N.d.T.] me alegraba... Esto sí, tal vez no es muy democrático decirlo, pero me parecía ilegal la presencia misma del MSI...".

${ }^{29}$ Cf., supra, nota 9. En la misma entrevista a Edith Bruck, ante la afirmación de la entrevistadora "Los únicos periódicos que admiran A Israel son los de derechas, y...", Levi observa: "Son aliados de defensores molestos. Su amor a Israel está claramente en función de su anticomunismo y en su expresión me parece ver admiración precisamente por aquellos aspectos de Israel que menos me gustan".

${ }^{30}$ Cf. Segrè, Giorgio: "Intervista a Primo Levi" ("Entrevista a Primo Levi”), Ha-tikwà. Organo della Federazione Giovanile Ebraica d'Italia, XXXI, no 207 (abril 1979), en Levi, Primo: Opere Complete, III, op. cit., pp. 145-149.

${ }^{31}$ Resolución 37/123, sección D 1-2.

${ }^{32}$ El texto integral del informe está disponible en inglés en la web del Ministerio de Asuntos Exteriores israelí: https://mfa.gov.il/MFA/ForeignPolicy/MFADocuments/ (agosto de 2019).
} 
("Para que Israel se retire"), firmado por Primo Levi y otros siete representantes de la intelectualidad judía italiana: Franco Belgrado, Edith Bruck, Ugo Caffaz, Miriam Cohen, Natalia Ginzburg, David Meghnagi y Luca Zevi. Su contenido era el siguiente:

"Como democrátas y judíos, hacemos un llamamiento a que el gobierno israelí retire de inmediato sus tropas del Líbano.

Reafirmamos la necesidad de una solución del conflicto que reconozca los derechos de todos los pueblos de la región a la soberanía y a la seguridad nacional.

Los que en otros momentos temblaron por la amenaza de destrucción del Estado de Israel deben hoy encontrar el valor y la fuerza de oponerse a la política del gobierno Beguín y a todo lo que representa para los destinos democráticos del estado de Israel y para la perspectiva de una convivencia pacífica con el pueblo palestino.

A Beguín le gusta presentarse como el intérprete más consecuente de las exigencias de seguridad de Israel. Su política, por el contrario, es lo más nefasto para la ordenación democrática de la sociedad israelí, atravesada por peligrosas tendencias exclusivistas. Tendencias que, en el caso de la amenaza de anexión de Cisjordania, poblada por más de un millón de árabes-palestinos, se demostrarían letales: las esperanzas de todos los que en la atormentada restitución de la península del Sinaí a Egipto habían visto un paso significativo en la dirección de una composición pacífica del conflicto de Oriente Próximo recibirían un ulterior y duro golpe.

De hecho, los destinos de la democracia israelí siguen indisolublemente unidos a las perspectivas de paz y de reconocimiento recíproco del pueblo palestino. Este pueblo paga trágicamente no sólo las culpas históricas de Occidente y de sus diversas iglesias, sino también las culpas antiguas y recientes del nacionalismo árabe y de la ideología islámica con respecto a los judíos.

La solución militar adoptada contra la OLP, solución que evoca un lenguaje de triste memoria para todo judío, se desarrolla con la connivencia de las fuerzas políticas israelíes que, sin embargo, se definen como fuerzas de oposición interna. Se trata de una política que puede tener como único resultado devolver con fuerza a toda la organización de la Resistencia Palestina a las posiciones que engendraron la masacre de Múnich $^{33}$ y el secuestro de Entebbe ${ }^{34}$. Hay que creer que la colusión entre el terrorismo antisemita y el integrismo panislámico evidenciada en el informe Mitterand saldrá reforzada por la invasión en curso. Existe también el riesgo de que una opinión pública cada vez más acostumbrada a las noticias de guerra que proceden de varios puntos del globo se vuelva progresivamente más indiferente ante eventuales nuevas manifestaciones de antisemitismo, como se ha podido advertir después del atentado a la sinagoga de Viena ${ }^{35}$.

Por todo esto, luchar contra la política del gobierno Beguín en este momento trágico para el pueblo palestino es más que un testimonio a favor de la retirada de las tropas israelíes del Líbano y del derecho a la autodeterminación del pueblo palestino. Es también un modo de luchar contra los gérmenes potenciales de un nuevo antisemitismo que se sumaría a las antiguas y nunca desaparecidas tendencias

\footnotetext{
${ }^{33}$ Atentado llevado a cabo por la organización palestina "Septiembre Negro", con la ayuda de grupos alemanes neonazis, que provocó la muerte de once atletas israelíes en las Olimpiadas de Múnich, entre el 5 y el 6 de septiembre de 1972.

${ }^{34}$ Secuestro de un avión de Air France procedente de Tel Aviv, con 248 pasajeros a bordo, llevado a cabo el 27 de junio de 1976 por terroristas palestinos y alemanes que obligaron al piloto a aterrizar en el aeropuerto de Entebbe, en Uganda. Una semana más tarde, el 4 de julio, una unidad de asalto del ejército israelí liberó a los rehenes en una operación en la que perdieron la vida decenas de personas.

${ }^{35}$ Llevado a cabo por terroristas de la OLP el 29 de agosto de 1981, provocó dos muertos y diecinueve heridos.
} 
antijudías que existen en el seno de la sociedad civil, en particular en los países gobernados por regímenes totalitarios.

El presente llamamiento quiere ser un marco capaz de incluir posiciones políticas que pueden ser incluso muy diferentes entre sí, pero que aspiran todas a una paz equitativa entre los pueblos de la Región.

Invitamos a suscribirlo (también mediante el envío de adhesiones a «La Repubblica») a todos los que viven la angustia de estas horas.

Franco Belgrado, Edith Bruck, Ugo Caffaz, Miriam Cohen,

Natalia Ginzburg, Primo Levi, David Meghnagi, Luca Zevi." ${ }^{36}$

El manifiesto se comenta solo: contiene afirmaciones y advertencias que no admiten réplica. Israel, esta vez, no tiene razón: el pueblo palestino, víctima de culpas no suyas, tiene pleno derecho al reconocimiento y a la paz, sin los cuales pierde sentido el mismo derecho a la existencia de un Israel democrático; los rescoldos antisemitas nunca apagados debajo de las superficies de los estados occidentales pueden avivar el fuego del terrorismo internacional uniéndose a las llamas crecientes del panislamismo; la opinión pública, cansada de tantas noticias bélicas, corre el riesgo de volverse indiferente ante las cada vez más comunes manifestaciones antisemitas que hieren Europa.

Poco antes del estallido del conflicto, Levi no sólo había vuelto por segunda vez a Auschwitz ${ }^{37}$, sino que había publicado también con éxito su primera novela, Se non ora, quando? ("Si ahora no, ¿cuándo?), historia de un grupo de partisanos judíos polacos y rusos que, entre 1943 y 1945, luchan para derrotar al enemigo, alcanzar Italia y viajar finalmente a Palestina. En palabras de Bellin, "Levi se encontró en una posición bastante incómoda. De repente, los combatientes judíos de Si ahora no, ¿cuándo? se habían transformado en algo que les recordaba a muchos a los nuevos opresores, guiados por los halcones Ariel Sharón y Menájem Beguín. Levi recibió cartas de lectores que consideraban la novela una forma de respaldo al sionismo militante de Beguín"38.

Quizá debido también a esta polémica, el 24 de junio, esta vez en primera plana de $L a$ Stampa, Levi volvió a hablar de la guerra, publicando un artículo titulado significativamente Chi ha coraggio a Gerusalemme? (“¿Quién tiene valor en Jerusalén?”) en el cual presentó algunas matizaciones que dieron lugar a reacciones encontradas.

"El azar ha querido que la noticia del ataque israelí al Líbano coincidiera para mí con un regreso a Auschwitz en calidad de guía para un grupo de visitantes. Las dos experiencias se han superpuesto de manera angustiosa, y todavía estoy intentando desenredar los motivos de mi angustia. Las marcas de la masacre de hace cuarenta años, en el lugar en el cual se llevó a cabo, están presentes todavía hoy: golpean como un mazazo. No sorprende que la matanza hitleriana haya estrechado los lazos entre los supervivientes, haciendo de ellos una nación en potencia, y les haya otorgado la portentosa voluntad con la que, en pocos años, vencieron a los países árabes coaligados y a la hostilidad inglesa, construyendo milagrosamente un nuevo Estado. La terrible violencia sufrida legitimaba en cierta medida la violencia ejercida: de hecho, Israel fue reconocido enseguida por todas las grandes potencias, primeras entre todas la Unión Soviética y los países del bloque oriental. En Israel se han reconocido e identificado, en mayor o menor medida, los judíos de la Diáspora: era el País de la Biblia, heredero de todas las corrientes de la cultura judía,

\footnotetext{
${ }^{36}$ Levi Primo (et al.): "Perché Israele si ritiri", La Repubblica, 16 de junio de 1982, p. 10.

${ }^{37}$ Cf. Ascarelli, Emanuele y Toaff, Daniel: "Ritorno a Auschwitz" ("Regreso a Auschwitz"), emisión televisiva de Rai 2 del 25 de abril de 1983, transcrita en Levi, Primo, Opere Complete, III, op. cit., pp. 348-358.

${ }^{38}$ Bellin, Stefano, op. cit., p. 85.
} 
la tierra redentora, la patria ideal de todos los judíos. Los decenios siguientes han erosionado y distorsionado esta imagen. El mundo árabe, repetidas veces derrotado en el campo, ha acumulado hacia Israel un odio intenso, reconociendo en el nuevo Estado el culpable de sus males seculares, empecinándose en su posición de rechazo. Como siempre sucede, al rechazo le ha respondido un rechazo; Israel, cada vez menos Tierra Santa, cada vez más país militar, va asumiendo los comportamientos de los demás países de Oriente Medio, su radicalismo, su desconfianza respecto a la negociación. El ataque actual al Líbano no es inmotivado, ha existido una larga provocación de la OLP, la OLP no ha condescendido nunca a un comienzo de negociación, se obstina en no reconocer a Israel (al que sigue llamando «la entidad sionista»); pero la violencia con la que se ha llevado a cabo el ataque ha asustado al mundo entero. No me da vergüenza admitir mi desgarro interior: el lazo que me una a este país sigue existiendo, percibo en cierto modo este país como mi segunda patria, quisiera que fuera distinto de todos los demás países; pero precisamente por esto siento angustia y vergüenza ante su última hazaña. Desconfío de los éxitos conseguidos mediante el uso sin escrúpulos de las armas. Siento indignación ante los que comparan apresuradamente a los generales israelíes con los generales nazis, y al mismo tiempo debo admitir que estos juicios Beguín se los está buscando. Veo con desaliento que la solidaridad de los países europeos se enrarece. Temo que esta iniciativa, espantosamente costosa en términos de sangre, inflija al judaísmo una degradación difícilmente curable y que contamine su imagen. Advierto en mí, no sin sorpresa, un vínculo sentimental profundo con Israel, pero no con este Israel. El problema palestino existe: no se puede eliminar, no se puede solucionar como quiere Arafat, negándole a Israel el derecho a existir, pero tampoco como quiere Beguín. Sadat no era ni un genio ni un santo, era sólo un hombre dotado de fantasía, sentido común y valor, y ha sido asesinado por haber emprendido un camino. ¿No hay nadie, en Israel o en otro lugar, que se sienta capaz de seguirlo?"39

No puede dejar de llamar la atención una afirmación como "la terrible violencia sufrida legitimaba en cierta medida la violencia ejercida", relativa a la "guerra de independencia" de 1948, o la referencia a los "males seculares" del mundo árabe que descarga de alguna manera a Israel de la total responsabilidad de la situación palestina. Tampoco puede dejar indiferente la aserción "El ataque actual al Líbano no es inmotivado", aunque con ella se quieran recordar las diferentes propuestas de acuerdo efectivamente rechazadas por las organizaciones palestinas a lo largo de los decenios anteriores. Con razón, se han señalado los límites de la argumentación de Levi: los palestinos no tuvieron nada que ver con los horrores del nacionalsocialismo alemán, de manera que la "terrible violencia" sufrida por los judíos no pudo en ningún momento justificar la violencia ejercida por los mismos contra aquellos; la "rigidez" de los países árabes con respecto a Israel era también consecuencia de la política de exclusión del Estado judío; "motivar" una guerra de invasión, finalmente, es algo ciertamente difícil. La crítica de Levi se dirigía no tanto contra el ataque en sí como contra el "uso sin escrúpulos de las armas" que empañaba la imagen del Israel bíblico - "tierra redentora", "patria ideal” de todos los judíos y, por ende, modelo de convivencia para la humanidad entera-, transformándola en la de un país militar cualquiera de Oriente Medio. A partir de aquel momento, el ritmo de las intervenciones de Levi en el debate público se intensificó.

\footnotetext{
${ }^{39}$ Levi, Primo: "Il contagio della violenza. Chi ha coraggio a Gerusalemme?” (“El contagio de la violencia. ¿Quién tiene valor en Jerusalén?"), La Stampa, 24 de junio de 1982, p. 1, en Levi Primo: Opere complete, II, op.cit., pp. 1528-1529.
} 
El 28 de junio, una vez más en La Repubblica, Levi publicó una especie de respuesta a los que lo habían acusado de comparar irresponsablemente la política israelí a la de la Alemania de Hitler. A la pregunta "¿Por qué algunos judíos italianos identifican hoy el drama palestino con las persecuciones sufridas hace cuarenta años?”, Levi contestó:

"No sólo judíos, también muchos no judíos lo hacen. Alguna analogía existe. Yo no quisiera llevar las cosas demasiado lejos, pero las analogías me parecen esencialmente éstas. Se trata de una «nación», llamémosla así, entre comillas, porque en el mundo árabe las cosas son siempre difíciles de definir, que se ha encontrado sin país. Y éste es un punto de contacto con los judíos. Existe una diáspora palestina reciente que tiene algo en común con la diáspora judía de hace dos mil años. Y la analogía no puede ir mucho más allá, a mi juicio. [...] Sin embargo me niego a asimilar lo que Hitler llamaba Solución final con las cosas que hacen los israelíes hoy, aun siendo éstas violentas y terribles. No existe un plan de exterminio del pueblo palestino. Esto significa ir demasiado lejos". ${ }^{40}$

El 5 de julio, en una entrevista concedida a Valeria Gandus para el semanario Panorama, Levi expresó su "desgarro, decepción y sorpresa" por la invasión del Líbano que le obligaba a "ajustar cuentas" con su conciencia y a revisar su imagen de Israel: "Pero ¿qué es ahora Israel? ¿La Tierra Santa? No, es una avanzadilla de guerra". Una vez más, el autor de Si esto es un hombre rechaza la ecuación Israel-Alemania nazi: "No creo que a los guerrilleros de la OLP se les mate en cuanto palestinos, sino, precisamente, en cuanto guerrilleros" 41 .

Juicios parecidos fueron expresados por Levi en sucesivas entrevistas publicadas en diferentes medios: el 14 de julio en el semanario Oggi, el 3-4 septiembre en el Corriere Medico, el 17 de septiembre en el semanario Época ${ }^{42}$.

Una semana después de la masacre de Sabrá y Chatila, el 24 de septiembre, de nuevo en las páginas de La Repubblica, apareció una entrevista firmada por Giampaolo Pansa titulada rotundamente Io, Primo Levi, chiedo le dimissioni di Begin ("Yo, Primo Levi, pido la dimisión de Beguín"), en la que Levi, también a raíz de la "espantosa mole" de cartas recibidas en aquellos días, intentó aclarar definitivamente su posición con respecto al conflicto en el Líbano. El texto, muy largo, contiene pasajes particularmente significativos para comprender la visión de Levi en su madurez.

Llamo a la puerta de Primo Levi. Tengo muchas preguntas en mi cuaderno y muchísimas en mi mente y en mi corazón. Sin embargo, es él quien rompe el silencio. Atravesándome con aquella mirada suya límpida y fría, dice, casi susurrando:

De acuerdo, hablemos... Pero le confieso que he aceptado esta entrevista con mucha indecisión....

\footnotetext{
${ }^{40}$ Stabile, Alberto: "Sì, Israele ha passato il segno ma non è giusto parlare di nazismo ("Sí, Israel ha colmado la medida pero no es justo hablar de nazismo"), La Repubblica, 28 de junio de 1982, en Levi, Primo: Opere Complete, III, op. cit., pp. 272-274.

${ }^{41}$ Gandus, Valeria: "Sono lacerato e deluso" ("Estoy desgarrado y decepcionado"), Panorama, XX, n. 284, 5 de julio de 1982, en Levi, Primo: Opere Complete, III, op. cit., pp. 281-282.

${ }^{42}$ Cf., en el orden, Jesurum, Stefano: "Si è offuscata la luce della stella d'Israele" ("Se ha ofuscado la luz de la estrella de Israel”), Oggi, XXXVIII, n. 27, 14 de julio de 1982, en Levi, Primo: Opere Complete, III, op. cit., pp. 283-287; Diwan, Fiona: "Sono un ebreo, ma non sono mai stato sionista" (Soy un judío, pero nunca he sido sionista"), Il Corriere Medico (suplemento semanal de Il Corriere della Sera, 3-4 de septiembre de 1982), p. 15, en Levi, Primo: Opere Complete, III, op. cit., pp. 293-297; Monticelli, Gabriella: “Dov’è finita la terra promessa?" (“¿Adónde ha ido a parar la tierra prometida?”), Epoca, XXXIII, n. 1667, 17 de septiembre de 1982, en Levi, Primo: Opere Complete, III, op. cit., pp. 298-302.
} 


\section{¿Por qué, Sr. Levi?}

Por dos razones. Una interna, mía: la guerra civil la llevo en las entrañas. La otra razón es que en estos días he recibido muchas cartas, una mole espantosa de cartas, por lo que he dicho y escrito en los últimos tiempos a propósito de la última guerra de Israel.

\section{¿Qué cartas eran?}

De disenso y de consenso. Y las cartas de disenso son de dos tipos. Unos disienten porque me consideran demasiado...

\section{¿Demasiado sionista?}

Sí, demasiado sionista. Otros, en cambio, me reprochan que no soy lo bastante sionista.

\section{¿Ha recibido también cartas con amenazas?}

No, no he recibido ninguna.

Usted, en estos días, ¿tiene miedo?

¿En qué sentido? ¿Personalmente o en cuanto perteneciente al pueblo judío?

\section{En ambos sentidos.}

Personalmente, no, no tengo miedo. El miedo es un hecho instintivo, profundo, y personalmente no tengo miedo. Pero tampoco tengo miedo en cuanto judío. No, para nosotros los judíos no siento que llegue ni un segundo Holocausto ni una matanza inminente de factura hitleriana. A lo sumo, siento dolor. Esta guerra de Israel, esta matanza de Beirut, están contaminando la imagen de los judíos en todo el mundo.

Señor Levi, ¿existe el riesgo de un nuevo antisemitismo? Le pregunto esto con temblor y horror...

Sí, en cierta medida este riesgo existe. Pero, de momento, se limita a episodios esporádicos. No es casual que este peligro se advierta sobre todo en París y en Bruselas. En Francia, desde el caso Dreyfus en adelante, el antisemitismo no murió nunca, se combina con el fondo xenófobo de los franceses.

Sin embargo, también en Milán la comunidad israelita denuncia amenazas y da señales de miedo. ¿Y en Turín?

Aquí no tengo noticias de que haya acontecido algo. Tal vez un par de pintadas habrán aparecido también en Turín, pero para hacer un par de pintadas es suficiente un imbécil con un espray. Además, en Turín existe una comunidad judía pequeña, muy compacta y orientada en sentido más liberal que la comunidad milanesa... En cualquier caso, sí, el antisemitismo es una bestia que vuelve a levantar la cabeza. Sin embargo, éste no es un argumento que nosotros los judíos de la Diáspora podamos oponerle a Beguín. No tiene sentido decirle a Beguín: no hagáis lo que estáis haciendo porque nos hacéis daño. Los argumentos son otros muy diferentes.

\section{¿Y cuáles son?}

Son dos, uno moral y otro político. El moral es el siguiente: ni siquiera una guerra justifica la arrogancia sanguinaria demostrada por Beguín y los suyos. El argumento político es igualmente claro: Israel está precipitándose rápidamente en el 
aislamiento total. Es un hecho tremendo, que nunca se había dado antes. Llegados a este punto, la conclusión es evidente: ni siquiera la razón de Estado, que a menudo Beguín y Sharón invocan, puede justificar las últimas decisiones del gobierno de Israel.

Señor Levi, usted dice: Beguín, Beguín, pero Beguín no es un líder aislado. Está en el gobierno con el consenso de la mayoría de los israelíes.

Me doy cuenta. Sí, lo sé, lo sé...

Y esto ¿qué le sugiere?

Una consideración obvia. Beguín se mantiene en pie, sobre todo gracias a los votos de los jóvenes y de los inmigrados recientes, es decir, no de los prófugos de Europa oriental, sino de aquellos judíos que proceden de los países de Oriente Medio o que han nacido en Israel. Es toda gente que siente una fuerte animadversión con respecto a los Estados cercanos, de los cuales a menudo procede, y esto, en cierta medida, explica esta guerra y lo que ha sucedido durante la guerra. Mi condena, de todas maneras, es total. Lo digo claramente. Y también tengo una esperanza, la misma que me ha llevado a aceptar esta entrevista: no me interesa que mis palabras tengan efecto en el lector italiano, me interesa que tengan efecto en Israel, en sus dirigentes, en el electorado, en los periodistas israelíes.

\section{¿Usted es influyente en Israel?}

No creo. De mis libros han traducido sólo La tregua. Pero esto no demuestra nada. En Israel leen también alemán e inglés, de manera que pueden conocer mis otros libros.

\section{$Y$ usted ¿qué mensaje les envía a los gobernantes israelíes?}

Que dimitan. No tengo otro mensaje, visto que es imposible cambiar sus cabezas. Ciertamente, sé bien que en un momento como éste pedirles también que dimitan es una utopía. Sin embargo, si les queda un atisbo de razón, Sharón debe dimitir.

\section{¿Qué hombre es Sharón?}

De Beguín conozco la historia. Pero no sé lo que es Sharón. La imagen que tengo de Sharón es sólo la actual, no conozco sus raíces.

\section{Hábleme de esta imagen actual...}

Beguín, Sharón, en resumen, todo el grupo que hoy dirige Israel se parece mucho a las clases dirigentes de los demás países de Oriente Medio. Paradójicamente, Beguín y los suyos están cumpliendo un antiguo sueño sionista: llegar a ser un país de Oriente Medio. Pero lo cumplen de la peor manera. Es decir, adecuándose a la demagogia, a la inestabilidad, a la escasa fe en las promesas y en las negociaciones que distinguen a demasiados dirigentes de Oriente Medio.

\section{¿Se puede definir a Sharón como fascista?}

Para Sharón no sé, porque, le repito, no conozco su historia. Sin embargo, para Beguín "fascista" es una definición que acepto. Creo que el mismo Beguín no la rechazaría. Ha sido discípulo de Jabotinski: éste era el ala derecha del sionismo, se proclamaba fascista, era uno de los interlocutores de Mussolini. Sí, Beguín ha sido su discípulo. La historia de Beguín es ésta. De Sharón comprendo sólo que es un militar duro y sin escrúpulos. Pero qué hay en su cabeza, yo, desde lejos, no lo veo. 
Oiga, señor Levi, hay una pregunta que hoy muchos se hacen. El fascismo ha vuelto a nacer en muchas partes del mundo. ¿Puede abrirse camino también en Israel? El fascismo en sentido propio, yo diría que no... pero la suya es una pregunta imprecisa. Borre la pregunta o hágamela de otra forma.

Entonces, vuelvo a hacérsela así: ¿Israel puede llegar a ser una Estado totalitario? Podría suceder, pero sólo con una guerra civil. Sin embargo, hoy veo que la oposición a Beguín viene, ciertamente, de una minoría, pero de una gran minoría. No, en Israel no creo que pueda suceder lo que ha sucedido en Chile. Este riesgo no lo veo. Israel es un país extremadamente vital desde el punto de vista político, democrático.

¿Usted quiere decir que Israel posee los anticuerpos para reaccionar ante este mal oscuro que lo aflige?

Diría que sí. Lo veo en las manifestaciones de estos días. Y, además, mis coetáneos de allí, y, por reflejo, sus hijos y sus nietos, poseen una experiencia directa de los horrores del fascismo en Europa.

Sin embargo, hay quien dice, y también nosotros de «La Repubblica» lo hemos escrito, que existe el riesgo de que el primer enemigo de los judios y del pueblo de Israel sea precisamente el Estado de Israel.

Me parece una afirmación un poco dura, y también genérica, que puede, a lo sumo, valer sólo como afirmación momentánea, es decir, para este momento, para el hoy.

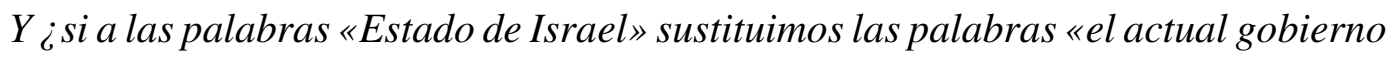
de Israel»?

Entonces sí. Pero el juicio correcto me parece el siguiente: el actual comportamiento del actual gobierno de Israel corre el riesgo de ser el peor enemigo de los judíos. De todas maneras, tampoco éste es un argumento que pueda oponérsele a Beguín. Un israelí podría contestar: «A nosotros ¿qué nos importan los riesgos que corráis vosotros? Nosotros tenemos nuestros problemas». Los argumentos verdaderos son los dos que he dicho antes. Y precisamente sobre la base de esos argumentos, tenemos nosotros derecho a decirle a Israel: hasta que las cosas sigan estando como están hoy, no podéis volverles a pedir ayuda ni económica ni moral a los judíos de la Diáspora. No, no podéis pedirles dinero a los judíos de la Diáspora que critican a Israel porque es militarista y después gastaros esas ayudas en armas.

Pero ¿no existe un problema de seguridad también militar para Israel?

Este tema rebasa mi competencia, pero creo de verdad que no. Beguín ha llevado a cabo esta guerra con la pasividad más completa de todos los Estados fronterizos y no fronterizos. La aniquilación del brazo armado palestino, la ha llevado a cabo Beguín con el consenso de todos.

\section{Ya, Arafat. Hablemos de Arafat...}

No me gusta Beguín, pero tampoco me gusta Arafat. No creo para nada en el ramo de olivo de Arafat. Es posibilista e inteligente, pero también carece de escrúpulos en la misma medida que Beguín. Y ha sido precisamente Beguín quien le ha regalado la victoria política y también el laurel de líder de todos los palestinos que antes no tenía. 


\title{
¿Qué dice de la acogida que Arafat ha tenido en Italia?
}

La he visto, la he visto... y mi reacción ha sido de desconfianza y también de irritación. Pero, lo repito, ha sido Beguín el que le ha dado a Arafat la gloria de la derrota.

Sin embargo, después de la derrota, se ha producido la masacre de los palestinos en los dos campos de Beirut. ¿Qué reacción instintiva ha tenido usted ante las noticias de lo que había sucedido allí?

Yo no tengo nunca reacciones instintivas. Si las tengo, las reprimo. En un primer momento, he tenido dudas respecto a lo que había sucedido realmente. Después he comprendido que era todo cierto. Entonces, la masacre en aquellos dos campos me ha recordado de cerca lo que hicieron los rusos en Varsovia en el mes de agosto de 1944: se quedaron parados a orillas del Vístula mientras los nazis exterminaban a los partisanos polacos. Ciertamente, como todas las analogías históricas, también la mía cojea. Sin embargo, también Israel, como entonces los soviéticos, habría podido intervenir y tenía la fuerza para parar a las bandas que masacraban a aquella gente, y no lo ha hecho.

\section{¿Por qué Israel no lo ha impedido?}

No lo sé, no lo sé... tal vez haya alguna verdad en las hipocresías de Beguín. Esa masacre no responde al estilo israelí. La situación debe habérseles escapado de las manos. Además, puede ser también que alguien haya querido perder tiempo a la hora de intervenir para defender a aquellas mujeres y a aquellos chicos... ¿cómo puedo decir algo más? Mire, yo conservo hacia Israel una cierta lealtad, un vínculo sentimental. No soy tan pesimista como para decir que Israel será siempre así.

\begin{abstract}
Pero ¿qué podéis hacer vosotros los judios y nosotros los no judios para que Israel no sea siempre así?

Usted dice: nosotros y vosotros... se equivoca. No hay diferencia. Si Dios quiere, por una vez no es discriminante ser judío o no judío. Hay sólo una respuesta válida para todos. Y no es, como alguien pide, la ruptura de relaciones diplomáticas o la suspensión de las relaciones económicas. Éstas serían reacciones sin sentido, útiles sólo para reforzar a Beguín.
\end{abstract}

\begin{abstract}
¿Entonces?
Debemos todos hacer dos o tres cosas. Darnos cuenta de la situación. Sofocar nuestros impulsos de solidaridad emotiva con Israel, para razonar con la cabeza fría acerca de los errores de la actual clase dirigente israelí. Derrocar a esta clase dirigente. Ayudar a Israel a recuperar sus orígenes europeos, es decir el equilibrio de sus padres fundadores, de Ben Gurión, de Golda Meir. No significa que todos éstos tuvieran las manos limpias, pero ¿quién tiene las manos limpias? Abba Eban, por ejemplo, me parece una garantía para el futuro de Israel, no es siquiera demasiado viejo ${ }^{43}$. Pero hoy es terrible. Yo recibo cartas desgarradoras de amigos que tengo allí. Se trata de hombres que han luchado en todas las guerras de Israel y
\end{abstract}

\footnotetext{
43 Aubrey Solomon Meir Eban (1915-2002), de origen surafricano, decidió cambiar su nombre en "Abba" ("Padre", en el sentido de "padre de la nación israelí") cuando, en 1946, en calidad de miembro del UNSCOP (United Nations Special Committee on Palestine), contribuyó de forma determinante a la aprobación de la Resolución 181 con la cual la Asamblea General de la ONU proponía el reparto de los territorios palestinos entre dos futuros estados, uno árabe y otro judío. El rechazo de dicha resolución por parte de los países árabes llevó al estallido de la guerra árabe-israelí de 1948. Abba Eban fue ministro de Relaciones Exteriores de Israel entre 1966 y 1974.
} 
han visto morir en la guerra a sus hijos. Me escriben: estás ciego, porque no ves toda la sangre israelí, la sangre judía vertida en estos años.

\section{$Y$ usted ¿qué les contesta?}

Contesto que me duele esta sangre como cualquier otra sangre vertida por hombres. Pero siguen siendo cartas desgarradoras. Y yo me siento desgarrado, también porque sé muy bien que Israel ha sido fundado por personas como yo, pero menos afortunadas que yo. Hombres con el número de Auschwitz tatuado en el brazo, sin casa y sin patria, que han sobrevivido a los horrores de la Segunda Guerra Mundial, que han encontrado allí una casa y una patria. Todo esto lo sé. Pero sé también que éste es el argumento favorito de Beguín. Y yo niego la validez de este argumento.

\section{Señor Levi, veo que es usted capaz de razonar con gran frialdad...}

Hago lo que puedo, aunque este tiempo es un tiempo de drama para nosotros. Hay una vieja comedia, escrita en el siglo pasado por Sholem Aleijem. ¿Sabe cuál es su título? Es difícil ser judio, hoy lo es más que nunca. Sí, hoy es más difícil ser judío. ${ }^{44}$

La entrevista nos devuelve la imagen de un Levi realmente desgarrado: la "guerra civil" que siente vibrar en sus entrañas y la persistencia del "vínculo sentimental" que lo une a un país que considera su segunda patria lo llevan a una ambigüedad sutil que es objeto de disputa entre sus lectores. La preocupación principal de Levi es la de la imagen que el Israel de Beguín y Sharón está dando al mundo, imagen "contaminada" de un país guiado por una élite sin escrúpulos, capaz de asistir impasible a una masacre después de haber favorecido la llegada al poder de un personaje equívoco como Arafat con tal de conseguir sus objetivos. Dicho con otras palabras, ya no puede afirmarse, como en 1967, que "Israel no está gobernado por locos" ${ }^{45}$ : el Israel de 1982 no ofrece garantías y ha perdido por tanto el derecho a presentarse como símbolo de moralidad, lo cual legitima, de alguna manera, las acciones en su contra ${ }^{46}$. Para defender la necesidad de oponerse a la transformación de Israel en un país más de Oriente Medio y a la violencia inaudita del conflicto en curso, Levi, rechazando el argumento de las consecuencias negativas de la política israelí para los judíos de la Diáspora, da dos razones fundamentales, razones que espera que puedan llegar a influir en la opinión pública, no tanto italiana como israelí: la inmoralidad sin discusión de cualquier uso indiscriminado de la fuerza y la evidencia del progresivo aislamiento del estado de Israel en la escena internacional. Aun admitiendo el riesgo de un nuevo brote de antisemitismo en una Europa que no ha conseguido nunca aniquilar la cepa de la xenofobia -y resulta realmente inquietante leer hoy día las alusiones a París y a Bruselas-, Levi confía en los anticuerpos democráticos de Israel, de los cuales, dicho sea de paso, la mencionada creación de la Comisión Cahan ofrecerá unos días más tarde un botón de muestra elocuente. En opinión de Levi, no sólo los judíos sino los demócratas del mundo entero deberían hacer "dos o tres cosas": reprimir los eventuales impulsos de solidaridad a priori a favor de Israel; comprender los errores cometidos por una clase dirigente apoyada por votantes judíos que, prófugos de los países fronterizos o nacidos en el mismo Israel después del conflicto mundial, alimentan razones de hostilidad hacia los árabes y no tienen memoria directa de la

\footnotetext{
${ }^{44}$ Pansa, Giampaolo: "Io, Primo Levi, chiedo le dimissioni di Begin ("Yo, Primo Levi, pido las dimisiones de Beguín”)", La Repubblica, 24 de septiembre de 1982, en Levi, Primo: Opere Complete, III, op. cit., pp. 303-309. 45 véase supra, nota 16.

${ }^{46}$ Resultaría extremadamente interesante, pero rebasaría los límites del presente trabajo, examinar aquí el problema de la "vergüenza" en Levi. Acerca de este sentimiento, cf., además de lo afirmado por el mismo Levi en dos textos citados más arriba (cf. notas 18 y 37), Agamben, Giorgio (1998): "Quel che resta di Auschwitz. L'archivio e il testimone", Turín, Bollati Boringhieri (ed. en español 2005): "Lo que queda de Auschwitz: el archivo y el textigo" (traducción de Antonio Gimeno Cuspinera), Valencia, Pre Textos); Harrowitz, Nancy Anne, op. cit., pp. 108-137 (“Shame's Identity”, con análisis de la lectura de Agamben).
} 
Shoah; derrocar al gobierno de Beguín y recuperar aquellas raíces europeas que, más allá de cualquier límite personal de los padres fundadores, constituían para el estado judío una garantía de equilibrio y de pluralismo. Levi parece no darse cuenta de la contradicción, inquietante de cara al futuro, que supone confiar en la existencia en Israel de una "experiencia directa de los horrores del fascismo en Europa", trasmitida de sus coetáneos a sus hijos y a sus nietos, y admitir, al mismo tiempo, que el gobierno Beguín se apoya en muchos jóvenes que no demuestran tener memoria alguna de los horrores pasados. En cualquier caso, Levi, modificando claramente el punto de vista presente en el manifiesto Perché Israele si ritiri suscrito en 1967, invalida el argumento de la "sangre judía" usado tanto a favor como en contra de la política del gobierno israelí: no sólo la sangre judía, sino "cualquier otra sangre vertida por hombres" duele. Por encima de cualquier nación o creencia está la humanidad. Y es precisamente ésta la intuición que Levi, como se verá a continuación, desarrollará en los años siguientes: la verdadera nación judía no se encuentra ya en el territorio del Estado de Israel, sino en aquella Diáspora para la cual Levi reivindica el discutido derecho a pronunciarse acerca de la política israelí.

\section{La Diáspora como “baricentro” del judaísmo: 1984-1987}

Tal vez a raíz del gran revuelo suscitado por sus declaraciones de 1982, Levi decidió guardar silencio acerca de la política israelí durante dos años. De hecho, sólo en 1984 aceptó concederle al periodista Gad Lerner una larga entrevista que apareció en el mes de septiembre en las páginas de L'Espresso. El título que los responsables del semanario eligieron para el artículo, haciéndose eco del título del primer y fundamental libro de Levi, no podía ser más provocador: Se questo è uno Stato ("Si esto es un Estado"). Pocos días antes de la publicación, el 13 de septiembre, había tomado posesión en Israel un nuevo y controvertido gobierno de coalición, guiado por el laborista Shimon Peres, cuyo ministro de Industria, Comercio y Trabajo era aquel mismo Sharón cuya dimisión habían pedido dos años antes Levi y, después de él, la mencionada Comisión Cahan. A la pregunta: los cambios en el mundo judío ¿son para bien o para mal?, Levi dio una respuesta que, aun siendo "tal vez la más difícil para él”, no dejaba de ser clara e iluminadora:

Me he convencido de que el rol de Israel como centro unificador del judaísmo en estos momentos -y subrayo "en estos momentos"- se encuentra en una fase de eclipse. Es preciso, por tanto, que el baricentro del judaísmo dé un giro, que vuelva a estar fuera de Israel, vuelva entre nosotros, los judíos de la Diáspora, que tenemos el cometido de recordarles a nuestros amigos israelíes la corriente judaica de la tolerancia. ${ }^{47}$

A pesar de la evidente incoherencia del nuevo gobierno y de la aparición en la escena política israelí de figuras como las del rabino ortodoxo de orígenes estadounidenses Meir Kahane, diputado en el nuevo Parlamento israelí y defensor de la necesidad de expulsar a todos los árabes de la Tierra Prometida, Levi mostró una vez más su confianza en las capacidades de regeneración democrática del Estado judío. Sin embargo, no pudo negar la angustia que le provocaba no tanto el riesgo de difusión de la intolerancia antiárabe -a su juicio reducido por la progresiva integración de los mismos árabes en la sociedad judía, con la excepción del "millón y medio de palestinos de Cisjordania"-, como la "normalización" de Israel, es decir, su acercamiento a la forma de ser de los demás países del mundo, con la relativa degeneración de

\footnotetext{
${ }^{47}$ Lerner, Gad: "Se questo è uno Stato" (“Si éste es un Estado"), L'Espresso, XXX, n. 39,30 de septiembre de 1984, en Levi, Primo: Opere Complete, II, pp. $462-467$ (cf. p. 462).
} 
la vida política y la progresiva pérdida de aquellas características que habían llevado a hablar de "milagro israelî" 48 .

En este sentido, es extremadamente interesante la parte final de la entrevista, en la que Levi corroboró su convicción de que el testigo del judaísmo había pasado de las manos de Israel a las de la Diáspora:

¿Qué es, pues, lo que le angustia, Señor Levi?

Antes que nada, el acuerdo entre el Likud y Alineamiento ${ }^{49}$, como cualquier otra gran coalición, me parece un remiendo provisional y paralizador, destinado a durar poco. Pero me refiero sobre todo al hecho de que antes de las elecciones se han abrazado tesis incluso repugnantes con el único objetivo de ganar votos. Ni siquiera sucede esto sólo en Israel, pero quizá estemos mal acostumbrados. Estamos acostumbrados a un Israel país de los milagros, al Israel de 1948, del sionismo que coincide con cierta idea de socialismo. Ahora asistimos a una degradación que es una normalización. Israel se está convirtiendo, desgraciadamente, en un país normal. Además, siendo un país de Oriente Medio, tiende a parecerse cada vez más a las demás naciones de aquella región. Por ejemplo, se puede temer el contagio entre el jomeinismo islámico y la difusión del integrismo religioso en Israel, aunque, en perspectiva, no me imagino a las masas israelíes prosternándose ante un nuevo ayatolá, sea éste Kahane o el mismo Sharón.

¿No cree usted que, habiendo nacido mayoritariamente en su Estado, los judios de Israel ya son diferentes respecto a los de la Diáspora, acostumbrados desde siempre a sentirse "minoría" en el país en el que viven, plasmados por su propia "diversidad"? Los judios europeos de los que usted habla en sus libros están dramáticamente agarrados al frágil valor de la tolerancia. ¿No será que, normalizándose, los israelies estén también cambiando su identidad?

Éste es un futuro previsible. Creo que somos nosotros, los judíos de la Diáspora, quienes debemos luchar. Recordarles a nuestros amigos israelíes que ser judío significa otra cosa. Custodiar celosamente la corriente hebraica de la tolerancia. Cierto, me doy cuenta de que así estoy tocando un punto crucial, es decir el interrogante: ¿dónde se encuentra hoy el baricentro del judaísmo?

Al menos desde 1948 en adelante, las principales instituciones sionistas no tienen dudas: el baricentro se encuentra en Israel.

No, lo he meditado durante mucho tiempo: el baricentro se encuentra en la Diáspora, vuelve a estar en la Diáspora. Yo, judío de la Diáspora, mucho más italiano que judío, preferiría que el baricentro del judaísmo se quedara fuera de Israel.

Esto podría sonar como el anuncio de su alejamiento de la nación israelí después de los cambios que ésta ha registrado.

No, en absoluto. Es el desarrollo de una relación profunda y pasional. Sólo creo que es mejor preservar la corriente principal del judaísmo en un lugar diferente de Israel. La cultura judía misma, especialmente la askenazí, está más viva en otros lugares, por ejemplo, en los Estados Unidos, donde es incluso determinante.

\footnotetext{
${ }^{48}$ Traverso, Enzo, (2013): La fin de la modernité juive. Historie d'un tournant conservateur, París Éditions La Découverte (ed. en español 2013: El final de la modernidad judía. Historia de un giro conservador (colección Prismas, vol. 8, traducción de Gustau Muñoz), Valencia, Universitat de València.

${ }^{49}$ Respectivamente, partido de derecha y coalición de centroizquierda israelíes.
} 
Por lo que usted dice, parece que quedarse en la Diáspora, es decir seguir siendo una comunidad minoritaria, sea casi condición obligatoria para perpetuar la identidad hebraica. Llevando la pregunta a los extremos, ¿el judio es judio en cuanto se encuentra en la Diáspora?

Diría sin duda que sí. Diría que lo mejor de la cultura hebraica está vinculado con el hecho de estar diseminada, de ser policéntrica.

Atribuyéndoles a los judíos de la Diáspora la tarea de educar a los israelíes en los valores del judaísmo, usted recibirá muchas reacciones irritadas. ¿No era lo contrario? ¿No era Israel quien infundía fuerza y seguridad en todos los judios del mundo?

Desgraciadamente, se debe hablar de un giro. De la fuente de la que sacaban fuerza, los judíos de la Diáspora sacan hoy motivo de reflexión y de tormento. Por esto hablo de eclipse, espero que momentáneo, del papel de Israel como centro unificador del judaísmo. Nosotros debemos apoyar a Israel, como nos piden también sus sedes diplomáticas, pero también debemos hacerle sentir el peso numérico, cultural, tradicional, incluso económico de la Diáspora. Tenemos el poder y también el deber de influir en alguna medida en la política israelí.

\section{¿En qué dirección?}

En primer lugar, creo que es preciso solicitar la retirada del Líbano. No menos urgente es paralizar los nuevos asentamientos en los territorios ocupados. Después de esto, como ya decía, es preciso perseguir, cautamente, pero con decisión, la retirada de Cisjordania y de Gaza.

\section{¿Y las relaciones con la OLP?}

La OLP es a su vez un Proteo, no se entiende bien cuál es hoy su rostro. De palabra, tiende la mano... Pero no, no creo que los tiempos estén maduros para un contacto con la OLP. El poder de Arafat está declinando, no sabemos qué hace, qué piensa, dónde está, ni siquiera sabemos si sigue siendo de veras el presidente de la OLP. Tal vez llegue el momento en que un gobierno israelí pueda tratar con la OLP, pero no hoy. Ambas partes se encuentran en fase fluida.

Si, como usted desea, el centro del judaísmo debe volver a vivir en la Diáspora, ¿será preciso que las comunidades israelitas despierten de alguna manera, que los judios vayan en busca de sus propias raíces y de su propia «diversidad» en el país en el que viven?

Sí. Aunque todavía no suceda, esto debería y podría suceder en un país como Italia, en el cual la comunidad judía es numéricamente exigua, pero más bien compacta. Éste es también nuestro límite: somos pocos y estamos integrados.

Hace dos años, después de la invasión del Líbano, usted dio vida, junto con otros judios italianos, a una protesta pública contra el gobierno israelí. ¿Es la indignación, por tanto, el resorte que puede unir a los judios de la Diáspora?

Hablemos, más serenamente, de desaprobación. Sí. Ése es un resorte, aunque yo tenga siempre idealmente ante mis ojos al israelí que me reprocha: “¿Es fácil para ti, judío italiano, sentando en un sillón, decidir por nosotros!”. Y sin embargo, insisto. La historia de la Diáspora ha sido, sí, una historia de persecuciones, pero ha sido también una historia de intercambios y de relaciones interétnicas y, por tanto, una escuela de tolerancia. Especialmente en Italia. Si estuviera menos cansado, si 
tuviera más fuerzas, actuaría en la comunidad israelita italiana para que asumiera este rol. Porque me parece bien la integración de los judíos en Italia, pero no su asimilación, su desaparición, la disolución de su cultura. Precisamente aquí en Turín tenemos el ejemplo positivo de una comunidad israelita integrada en la vida y en la cultura de la ciudad, pero no asimilada.

\section{¿Es difícil, para alguien que piensa como usted, la relación con las instituciones hebraicas e israelies? \\ Hablaría de una relación cariñosa y polémica. Ciertamente profunda. Porque estoy convencido de que Israel debe ser defendido, porque creo en la dolorosa necesidad de un ejército eficiente. Pero estoy convencido de que también para el gobierno israelí es bueno confrontarse con un apoyo de nuestra parte que sea siempre un apoyo condicionado ${ }^{50}$.}

Podría decirse que la entrevista concedida a Gad Lerner ofrece un excelente compendio de la visión que Levi tuvo de Israel al final de su vida, visión ciertamente no exenta de pequeñas grietas, pero sin duda alguna coherente y cargada de semillas que, de haber dado frutos, podrían haber contribuido a mejorar la todavía dramática situación de Oriente Medio. Como se ha visto, Levi no negó nunca los errores, grandes o pequeños, cometidos por el Estado judío, aunque sea innegable que algunas de sus declaraciones más antiguas contenían pruebas de descargo u omisiones a favor de Israel que alteraban sustancialmente el cuadro de la realidad, como la crítica más reciente ha evidenciado con toda la ecuanimidad de la que ha sido capaz. En las declaraciones de 1984 se vislumbra, una vez más, una contradicción entre la conciencia incluso orgullosa - propia de un hombre que llegó a definirse "italiano al 95 por ciento y judío al 5"51 de que "lo mejor de la cultura hebraica está vinculado con el hecho de estar diseminada, de ser policéntrica" y el deseo de que el "baricentro del judaísmo" vuelva a estar en Israel, deseo ciertamente no declarado, pero implícito en el "subrayado" de la temporalidad de la crisis del estado judío ("[...] Israel como centro unificador del judaísmo en estos momentos -y subrayo "en estos momentos"- se encuentra en una fase de eclipse [...]", y también, poco después, "[...] hablo de eclipse, espero que momentáneo, del rol de Israel como centro [...]).

A Levi no le gustaban los signos de admiración, prefiriendo, sin duda, los interrogantes. Su moverse constantemente en el límite de la contradicción se debía a la conciencia, manifestada en muchísimas páginas, de la imposibilidad de poseer una verdad absoluta, una verdad última. Para Levi era imposible ignorar los vínculos que lo unían con Israel, así como era imposible olvidar lo "irreversible" de Auschwitz" ${ }^{52}$ Sin embargo, más allá de cualquier vínculo, más allá de cualquier horror, Levi creía en el valor supremo de la libertad individual como única base segura de la democracia auténtica. Cuando, en el mes de mayo de 1986, Francesco Ciafaloni, en una entrevista dedicada al tema "Ética y política", le preguntó "¿Te parece que tiene sentido, en democracia, en el respeto de la separación del juicio ético y del juicio político, pedir que la práctica política respete la ética predominante de los ciudadanos?", Levi contestó con palabras serenas, pero capaces, una vez más, de suscitar la polémica: "Mi

\footnotetext{
${ }^{50}$ Lerner, Gad, op. cit, pp. 462-467.

${ }^{51}$ De un diálogo con los estudiantes de Pesaro mantenido el 5 de mayo de 1986 y publicado en Constantini, Luciana y Togni, Orietta: Il gusto dei contemporanei. Quaderno numero sette. Primo Levi, Pesaro, Banca Popolare Pesarese e Ravennate, 1990, pp. 5-10, 13-16, 19-22, en Levi, Primo: Opere Complete, III, op. cit., pp. 748-778 (cf. p. 759).

52 Borgia, Lucia: "Il veleno di Auschwitz" ("El veneno de Auschwitz”), Ragioni di una vita, transmisión televisiva de la Rai del 3 de febrero de 1985, transcrita en Levi, Primo: Opere Complete, III, op. cit., pp. $531-537$ (cf. p. 532 ): “-Adorno había escrito que después de Auschwitz ya no se puede crear poesía. -Mire, yo corregiría ese enunciado de Adorno. Diría que después de Auschwitz ya no se puede crear poesía si no es acerca de Auschwitz o, al menos, sin tener en cuenta Auschwitz. Algo con Auschwitz, algo irreversible ha sucedido en el mundo".
} 
generación ha visto el proceso de Núremberg. Era ilegal, pero necesario, precisamente para establecer esta distinción: algunas cosas no se deben hacer en ningún caso; aunque presuntamente sean útiles, no se deben hacer. No, ciertamente, por parte de nuestra conciencia profunda, cristiana, si quieres. Nuestro país puede cometer errores. En ese caso tenemos el derecho a tomar distancia de lo que hacen los políticos. Y así también en América. Todo americano tiene derecho a mostrar desaprobación y la suma de la desaprobación de los individuos tiene un peso, debe tenerlo". 53

\section{Conclusión}

Los documentos examinados hasta aquí permiten dibujar una imagen de un Primo Levi que, fiel a su formación académica, decidió en todo momento reprimir las que podrían considerarse reacciones instintivas para analizar "químicamente" la realidad política nacional e internacional. El objetivo del autor de Si esto es un hombre fue siempre el de identificar los diferentes elementos que componían el caldo de cultivo de la actualidad para comprender y prever las interacciones entre los mismos. En concreto, el juicio que Levi dio de la realidad política israelí se fue modificando a lo largo de los años, pasando de una cierta idealización inicial -fruto inevitable no sólo de sus orígenes familiares sino también y sobre todo de su experiencia "irreversible" en Auschwitz- hasta el rechazo abierto de una estrategia militarista que, minando las posibilidades de una convivencia pacífica con el pueblo palestino, ponía en serio peligro los destinos democráticos del mismo estado judío. En la visión del último Levi, Israel había perdido el derecho a presentarse como símbolo de moralidad y el centro de gravedad del judaísmo había vuelto a encontrarse en la Diáspora en cuanto portadora de aquella tolerancia sin la cual se hacen imposibles la libre expresión del individuo y la consiguiente existencia de la democracia.

\footnotetext{
${ }^{53}$ Ciafaloni, Francesco: "Etica e politica” (“Ética y política”), Ex Machina, II, n. 4 (mayo-junio 1986), en Levi, Primo: Opere Complete, III, op. cit., pp. 592-596 (cf. pp. 595-596). Cf. también lo declarado en 1982 a Jesurum, Stefano: "Si è offuscata la luce...", op. cit. (cf., supra, nota 39): “- Levi, mire, ésta es una carta muy larga que nos ha enviado Daniela Londner, una israelí de origen italiano, lectora de «Oggi». Defiende a Israel, dice un montón de cosas justas y verdaderas, habla de masacres terroristas de la OLP, narra la angustia de un pueblo siempre en guerra, nos escribe acerca de su realidad de madre de hijos perennemente obligados a defenderse con las armas... ¿Usted no tiene remordimientos? ¿No tiene dudas? —Ciertamente, tengo muchísimas. Las personas como usted, que me hace esta entrevista, y como yo, no tienen certidumbres... - Por suerte. Precisamente. Lo he declarado mil veces: no estoy exento de un vínculo sentimental con Israel. Estas posiciones de disociación y de condena están siempre llenas de turbación, de emociones, de sufrimientos. Pero creo que una persona, si es demócrata, tiene que ser demócrata, antes que nada. Si los argentinos se han equivocado invadiendo las Malvinas, Israel se ha equivocado de la misma manera. Puede haber unos atenuantes, pero los principios valen siempre".
} 


\section{Bibliografía}

\section{Repertorios bibliográficos}

Cf. el Opac de la WEB del Centro internazionale di studi Primo Levi (www.primolevi.it): http://opac.primolevi.it/Opac/RicercaLibera.aspx (agosto 2019).

II. Obras de Primo Levi

a. En italiano

\section{Libros}

Levi, Primo, (2016-2018): Opere complete (al cuidado de Marco Belpoliti), Turín, Einaudi.

Levi, Primo (2014): La tregua, Turín, Einaudi.

Levi, Primo (2014): Il sistema periodico, Turín, Einaudi.

2. Articulos y textos varios

Levi Primo: "Migliaia di cittadini partecipano alla manifestazione per Israele" ("Miles de ciudadanos participan en la manifestación a favor de Israel"), La Stampa, 1 de junio de 1967, p. 2.

Levi, Primo, "Una città solidale con Israele" ("Una ciudad solidaria con Israel”), La Stampa, 7 de junio de 1967, p. 6.

Levi, Primo: "Più che ogni altro paese, Israele dovrà vivere" ("Más que cualquier otro país, Israel deberá vivir"), Resistenza. Giustizia e Libertà, XXI, n. 7 (7 de julio de 1967), p. 5, en Levi, Primo: Opere complete, II, pp. 1350-1353

Levi, Primo: "Gli incontri nei Kibutz" ("Los encuentros en los kibutz"), Resistenza. Giustizia e libertà, XXII, n. 4 (abril 1968), p. 7, en Levi, Primo: Opere complete, II, pp. 1354-1356.

Levi Primo (et al.): "Perché Israele si ritiri”, La Repubblica, 16 de junio de 1982, p. 10.

Levi, Primo: "Il contagio della violenza. Chi ha coraggio a Gerusalemme?", La Stampa, 24 de junio de 1982, p. 1, en Levi Primo: Opere complete, II, pp. 1528-1529.

Levi Primo: "Il gusto dei conteporanei" ("El gusto de los contemporáneos"), diálogo con los estudiantes de Pesaro mantenido el 5 de mayo de 1986 y publicado en Constantini, Luciana y Togni, Orietta: Il gusto dei contemporanei. Quaderno numero sette. Primo Levi, Pesaro, Banca Popolare Pesarese e Ravennate, 1990, pp. 5-10, 13-16, 19-22, en Levi, Primo: Opere Complete, III, pp. 748-778.

b. En español

Levi, Primo (2018): Trilogía de Auschwitz (traducción de Pilar Gómez Bedate, introducción de Antonio Muñoz Molina), Barcelona, Península.

Levi, Primo (2014): El sistema periódico (traducción de Carmen Marín Gaite), Barcelona, Península.

\section{Entrevistas a Primo Levi}

\section{a. En lengua original}

Ascarelli, Emanuele y Toaff, Daniel: "Ritorno a Auschwitz" ("Regreso a Auschwitz"), emisión televisiva de Rai 2 del 25 de abril de 1983, transcrita en Levi, Primo, Opere Complete, III, pp. 348-358.

Borgia, Lucia: "Il veleno di Auschwitz" ("El veneno de Auschwitz”), Ragioni di una vita, 
emisión televisiva de la Rai del 3 de febrero de 1985, transcrita en Levi, Primo: Opere Complete, III, op. cit., pp. 531-537.

Bruck, Edith: "Ebreo fino a un certo punto" ("Judío hasta cierto punto"), Il Messaggero, 9 de enero de 1975, en Levi, Primo: Opere Complete, III, pp. 85-88.

Camon, Ferdinando (2014): Conversazione con Primo Levi, Milán, Gruppo Editoriale Mauri Spagnol, en Levi, Primo: Opere Complete, III, pp. 830-858.

Ciafaloni, Francesco: "Etica e politica" ("Ética y política"), Ex Machina, II, n. 4 (mayo-junio 1986), en Levi, Primo: Opere Complete, III, pp. 592-596.

De Rienzo, Giorgio: "In un alambicco quanta poesia”, Famiglia Cristiana, 29 (20 de julio de 1975), en Poliu, Grabriella y Calcagno, Giorgio (eds.) (1992): Echi di una voce perduta. Incontri, interviste e conversazioni con Primo Levi, Milán, Mursia.

Diwan, Fiona: "Sono un ebreo, ma non sono mai stato sionista" ("Soy un judío, pero nunca he sido sionista"), Il Corriere Medico (suplemento semanal de Il Corriere della Sera, 3-4 de septiembre de 1982), p. 15, en Levi, Primo: Opere Complete, III, pp. 293-297.

Gandus, Valeria: "Sono lacerato e deluso" ("Estoy desgarrado y decepcionado"), Panorama, XX, n. 284 (5 de julio de 1982), en Levi, Primo: Opere Complete, III, pp. 281-282.

Greer, Germaine: “Talks to Primo Levi”, The Literary Review, n. 89 (noviembre 1985), pp. 1519, (con traducción italiana de Erminio Corti) en Levi, Primo: Opere Complete, III, pp. 568577.

Grieco, Giuseppe: "Io e Dio. Non l'ho mai incontrato, neppure nel «Lager»" ("Yo y Dios. No lo he encontrado nunca, ni siquiera en el «lager»"), Gente, 48, 9 de diciembre de 1983, en Levi, Primo: Opere Complete, III, pp. 385-391.

Jesurum, Stefano: "Si è offuscata la luce della stella d'Israele" ("Se ha ofuscado la luz de la estrella de Israel”), Oggi, XXXVIII, n. 27 (14 de julio de 1982), en Levi, Primo: Opere Complete, III, pp. 283-287.

Lerner, Gad: "Se questo è uno Stato" (“Si esto es un Estado”), L'Espresso, XXX, n. 39 (30 de septiembre de 1984), en Levi, Primo: Opere Complete, II, pp. 462-467.

Lo Presti, Virgilio: "Tornare, mangiare, raccontare" ("Volver, comer, narrar"), Lotta Continua, 18 de junio de 1979, en Levi, Primo: Opere Complete, III, pp. 158-164.

Luce, Dina: "Il suono e la mente" ("El sonido y la mente”), emisión radiofónica del 4 de octubre de 1982, en Levi, Primo: Opere Complete, III, pp. 310-320.

Monticelli, Gabriella: "Dov’è finita la terra promessa?” (“¿Adónde ha ido a parar la tierra prometida?"), Epoca, XXXIII, n' 1667, 17 de septiembre de 1982, en Levi, Primo: Opere Complete, III, pp. 298-302.

Pansa, Giampaolo: "Io, Primo Levi, chiedo le dimissioni di Begin ("Yo, Primo Levi, pido la dimisión de Beguín")", La Repubblica, 24 de septiembre de 1982, en Levi, Primo: Opere Complete, III, pp. 303-309

Segrè, Giorgio: "Intervista a Primo Levi" ("Entrevista a Primo Levi”), Ha-tikwà. Organo della Federazione Giovanile Ebraica d'Italia, XXXI, n 207, abril 1979, en Levi, Primo: Opere Complete, III, pp. 145-149.

Stabile, Alberto: "Sì, Israele ha passato il segno ma non è giusto parlare di nazismo ("Sí, Israel ha colmado la medida pero no es justo hablar de nazismo"), La Repubblica, 28 de junio de 1982, en Levi, Primo: Opere Complete, III, pp. 272-274. 


\section{b. En español}

Levi, Primo (1998): Entrevistas y conversaciones (ed. de Marco Belpoliti, traducción de Francesc Miravitlles), Barcelona, Península.

\section{Biografías de Primo Levi}

Angier, Carole (2002): The Double Bond: Primo Levi. A Biography, Londres, Viking.

Anissimov, Myriam (1996): Primo Levi ou la tragédie d'un optimiste, París, Jean-Claude Lattès, (ed. en español 2001: Primo Levi o la tragedia de un optimista (traducción de Teresa Garín Sanz de Bremond), Madrid, Editorial Complutense.

Belpoliti, Marco (2015): Primo Levi di fronte e di profilo, Milán, Guanda.

Dini, Massimo y Jesurum, Stefano (1992): Primo Levi. Le opere i giorni, Milán, Rizzoli.

Thomson, Ian (2002): Primo Levi. A life, Londres, Hutchinson (ed. norteamericana: Nueva York, Henry Holt and Company, 2003; ed. en español 2007: Primo Levi. Una vida (traducción de Julio Paredes), Barcelona, Belacqua.

\section{Estudios}

Anónimo: "Il governo d'Israele attaccato in Parlamento" ("El Gobierno de Israel atacado en el Parlamento"), L'Unità, 17 de febrero de 1953

Bellin, Stefano: "The wound and the hope: Primo Levi's troubled relationship with Israel", Nemla Italian Studies Special Issue: The Jewish Experience in Contemporary Italy, 37 (2015), pp. 71-96.

Belpoliti, Marco: "Primo Levi, Auschwitz, la Liberazione: il carteggio inedito", L'Espresso ,10 de abril de 2017.

Brillanti, Claudio (2018): Le sinistre italiane e il conflitto arabo-israeliano-palestinese: 19481973, Roma, Sapienza Università Editrice.

Constantini, Luciana y Togni, Orietta: Il gusto dei contemporanei. Quaderno numero sette. Primo Levi, Pesaro, Banca Popolare Pesarese e Ravennate, 1990, pp. 5-10, 13-16, 19-22.

Di Figlia, Matteo (2012): Israele e la sinistra: gli ebrei nel dibattito pubblico italiano dal 1945 a oggi, Roma, Donzelli.

Eldar, Akiva y Zertal, Idith (2013): Les seigneurs de la terre. Histoire de la colonisation israélienne des territoires occupés, París, Seuil.

Harrowitz, Nancy Anne (2017): Primo Levi and the Identity of a Survivor, Toronto-BuffaloLondres, Toronto University Press.

Mieli, Paolo: "E gli ebrei rifiutarono il ricatto antisionista" ("Y los judíos rechazaron el chantaje antisionista"), Corriere della Sera, 15 de mayo de 2012, p. 38.

Mieli, Paolo (2017): Il caos italiano. Alle radici del nostro dissesto, Milán, Rizzoli.

Pasolini, Pier Paolo: "Israele" (“Israel”), Nuovi Argomenti, Nuova Serie nº 6 (abril-junio de 1967).

Molinari, Maurizio (1995): La sinistra e gli ebrei in Italia, 1967-1993, Milán, Corbaccio.

Poliu, Grabriella y Calcagno, Giorgio (eds.) (1992): Echi di una voce perduta. Incontri, interviste e conversazioni con Primo Levi, Milán, Mursia.

Rondini, Andrea (2012): Anche il cielo brucia. Primo Levi e il giornalismo, Macerata, Quodlibet. 
Said, Edward W. (1992): The Question of Palestine, Nueva York, Vintage.

Scarantino, Sergio: "Il dibattito storiografico sulla guerra dei Sei giorni”, Studi Storici, año 49, n. 1 (enero-marzo 2008), pp. 135-175.

Sereni, Ada (1973): I clandestini del mare. L'emigrazione ebraica in terra d'Israele dal 1945 al 1948, Milán, Mursia, cit. en Speelman, Raniero: "Primo Levi, Giorgio Pressburger e Israele", en Speelman, Raniero, Tonello; Elisabetta y Gaiga, Silvia (eds.) (2014): Atti del convegno Ricercare le radici: Primo Levi lettore - Lettori di Primo Levi. Nuovi studi su Primo Levi, (colección Italianistica Ultraiectina. Studies in Italian Language and Culture, 8), Utrecht, Igitur Publishing, pp. 225-236.

Speelman, Raniero: "Primo Levi, Giorgio Pressburger e Israele", en Speelman, Raniero, Tonello; Elisabetta y Gaiga, Silvia (eds.) (2014): Atti del convegno Ricercare le radici: Primo Levi lettore - Lettori di Primo Levi. Nuovi studi su Primo Levi, (colección Italianistica Ultraiectina. Studies in Italian Language and Culture, 8), Utrecht, Igitur Publishing, pp. 225236.

Thomson, Ian: "Primo Levi's Correspondence with Hety Schmitt-Maas", en Pugliese, Stanislao G. (2011): Primo Levi's Science and Humanism after the Fall, Nueva York, Fordham University Press.

Traverso, Enzo, (2013): La fin de la modernité juive. Historie d'un tournant conservateur, París Éditions La Découverte (ed. en español 2013: El final de la modernidad judía. Historia de un giro conservador (colección Prismas, vol. 8) (traducción de Gustau Muñoz), Valencia, Universitat de València.

Vidal-Naquet, Pierre (1981): Les Juifs, la mémoire et le présent, París, Maspero (ed. en español 1996: Los Judios, la memoria y el presente (traducción de Daniel Zadunaisky), México, Fondo de Cultura Económica.

Zertal, Idith (1998): From Catastrophe to Power: Holocaust Survivors and the Emergence of Israel, Londres, University of California Press.

Zertal, Idith (2005): Israel's Holocaust and the Politics of Nationhood (trans.by Chaya Galai), Cambridge, Cambridge University Press (ed. española 2010: La nación y la muerte: la Shoá en el discurso y la política de Israel (traducción de Marta Pino Moreno), Madrid, Gredos.

Zertal, Idith y Eldar, Akiva (2013): Les seigneurs de la terre. Histoire de la colonisation israélienne des territoires occupés, París, Seuil. 